\title{
Conditional Deletion of Hippocampal CA2/CA3a Oxytocin Receptors Impairs the Persistence of Long-Term Social Recognition Memory in Mice
}

\author{
ำ $Y$-Ting Lin, ${ }^{1,2}$ Tsan-Yu Hsieh, ${ }^{1}$ Tsung-Chih Tsai, ${ }^{2}$ Chien-Chung Chen, ${ }^{1,2}$ Chiung-Chun Huang, ${ }^{1}$ and $\odot$ Kuei-Sen Hsu ${ }^{1,2}$ \\ ${ }^{1}$ Department of Pharmacology and ${ }^{2}$ Institute of Basic Medical Sciences, College of Medicine, National Cheng Kung University, Tainan 70101, Taiwan
}

Oxytocin (OXT) receptors (OXTRs) are prominently expressed in hippocampal CA2 and CA3 pyramidal neurons, but little is known about its physiological function. As the functional necessity of hippocampal CA2 for social memory processing, we tested whether CA2 OXTRs may contribute to long-term social recognition memory (SRM) formation. Here, we found that conditional deletion of Oxtr from forebrain $\left(\mathrm{Oxtr}^{-I-}\right)$ or CA2/CA3a-restricted excitatory neurons in adult male mice impaired the persistence of long-term SRM but had no effect on sociability and preference for social novelty. Conditional deletion of CA2/CA3a Oxtr showed no changes in anxiety-like behavior assessed using the open-field, elevated plus maze and novelty-suppressed feeding tests. Application of a highly selective OXTR agonist $\left[\mathrm{Thr}^{4}, \mathrm{Gly}^{7}\right]$-OXT to hippocampal slices resulted in an acute and lasting potentiation of excitatory synaptic responses in CA2 pyramidal neurons that relied on $N$-methyl-D-aspartate receptor activation and calcium/calmodulin-dependent protein kinase II activity. In addition, $O x \mathrm{xr}^{-1-}$ mice displayed a defect in the induction of long-term potentiation, but not long-term depression, at the synapses between the entorhinal cortex and CA2 pyramidal neurons. Furthermore, Oxtr deletion led to a reduced complexity of basal dendritic arbors of CA2 pyramidal neurons, but caused no alteration in the density of apical dendritic spines. Considering that the methodologies we have used to delete Oxtr do not rule out targeting the neighboring CA3a region, these findings suggest that OXTR signaling in the CA2/CA3a is crucial for the persistence of long-term SRM.

Key words: CA2/CA3a; hippocampus; long-term potentiation; oxytocin; oxytocin receptor; social recognition memory

Significance Statement

Oxytocin receptors (OXTRs) are abundantly expressed in hippocampal CA2 and CA3 regions, but there are little known about their physiological function. Taking advantage of the conditional Oxtr knock-out mice, the present study highlights the importance of OXTR signaling in the induction of long-term potentiation at the synapses between the entorhinal cortex and CA2 pyramidal neurons and the persistence of long-term social recognition memory. Thus, OXTRs in the CA2/CA3a may provide a new target for therapeutic approaches to the treatment of social cognition deficits, which are often observed in patients with neuropsychiatric disorders.

\section{Introduction}

The hippocampus is a crucial structure for the acquisition and recall of episodic memory (Bird and Burgess, 2008). It comprises

Received July 5, 2017; revised Nov. 17, 2017; accepted Dec. 18, 2017.

Author contributions: Y.-T.L., T.-Y.H., T.-C.T., C.-C.C., C.-C.H., and K.-S.H. designed research; Y.-T.L., T.-Y.H., T.-C.T., C.-C.C., and C.-C.H. performed research; Y.-T.L., T.-Y.H., T.-C.T., C.-C.C., and C.-C.H. analyzed data; Y.-T.L., T.-Y.H., C.-C.H., and K.-S.H. wrote the paper.

This work was supported by research grants from the National Health Research Institute (NHRI-EX106-10613NI) and Ministry of Science and Technology (MOST 105-2321-B-006-017, 106-2321-B-006-018 and 106-2320-B-006026-MY3), Taiwan. We thank Dr. Katsuhiko Nishimori for kindly providing litters for breeding of Oxtr Venus-Neo/+ mice, and the technical services provided by the Bio-image Core Facility of the National Core Facility Program for Biotechnology, Ministry of Science and Technology, Taiwan.

The authors declare no competing financial interests.

Correspondence should be addressed to Dr. Kuei-Sen Hsu, Department of Pharmacology, College of Medicine, National Cheng Kung University, No. 1, University Road, Tainan 70101, Taiwan. E-mail: richard@mail.ncku.edu.tw. three cornu ammonis (CA) subregions, including the CA1, CA2, and CA3. Compared with the CA1 and CA3, the CA2 has not yet been extensively investigated. Anatomically, CA2 pyramidal neurons have morphology similar to those in the CA3 (Lorente de Nó, 1934; Ishizuka et al., 1995), despite a lack of the specialized thorny excrescences that are dendritic characteristic of CA3 pyramidal neurons. In addition, CA2 pyramidal neurons exhibit unique connectivity with intra- and extra-hippocampal structures. Prominent glutamatergic inputs to CA2 pyramidal neurons come from the dentate gyrus, CA3 pyramidal neurons and the entorhinal cortex (EC; Kohara et al., 2014; Chevaleyre and 
Piskorowski, 2016). Furthermore, CA2 pyramidal neurons receive afferent inputs from the septum, medium raphe nucleus, basal nucleus of the amygdala, and hypothalamic paraventricular and supramammillary nuclei (Haglund et al., 1984; Pikkarainen et al., 1999; Cui et al., 2013; Zhang and Hernández, 2013; Chevaleyre and Piskorowski, 2016). Although little is known about its functional properties and physiological roles, growing evidence suggests that the CA2 is more than a passive transition region between the CA1 and CA3. For instance, recent studies report that the CA2 may mediate social recognition and play an important role in social memory formation (Hitti and Siegelbaum, 2014; Stevenson and Caldwell, 2014; Smith et al., 2016), but its mode of action remains unclear.

Oxytocin (OXT) is a nonapeptide hormone that is synthesized and released from the supraoptic nucleus and paraventricular nucleus (PVN) of the hypothalamus to regulate a wide range of social (e.g., aggression, affiliation, bonding, and social recognition) and nonsocial behaviors (e.g., anxiety, stress, depression and learning and memory; Neumann, 2008; Neumann and Landgraf, 2008; Lee et al., 2009; Meyer-Lindenberg et al., 2011). OXT exerts its biological effects by binding to specific OXT receptors (OXTRs), the G-protein-coupled receptors that are coupled to phospholipase $\mathrm{C}$ through $\mathrm{G}_{\alpha \mathrm{q} / 11}$ (Gimpl and Fahrenholz, 2001). OXTRs are widely expressed throughout the brain with especially prominent expression in the hippocampus, amygdala, striatum, suprachiasmatic nucleus, bed nucleus of stria terminalis, piriform cortex, auditory cortex, and brainstem (Buijs and Swaab, 1979; Sofroniew, 1983; Young and Gainer, 2003; MeyerLindenberg et al., 2011; Grinevich et al., 2016; Mitre et al., 2016). Intriguingly, OXTRs have a highly restricted pattern of distribution in the hippocampus, being predominantly expressed in pyramidal neurons within the CA2 and CA3 (Yoshida et al., 2009). OXTR agonist has been shown to enhance synaptic transmission at Schaffer collateral $\rightarrow$ CA2 synapses (Pagani et al., 2015). Moreover, we have recently shown that OXT can stimulate hippocampal neurogenesis via OXTRs expressed in CA3 pyramidal neurons (Lin et al., 2017). Owen et al. (2013) have previously demonstrated that OXT can enhance hippocampal spike transmission in CA1 pyramidal neurons by increasing fast-spiking GABAergic interneuron activity. Despite these findings, the physiological functions of CA2 OXTRs have not yet been clearly explained. Social recognition memory (SRM), the ability of an individual to distinguish familiar from novel conspecifics, is critical for display of appropriate social behaviors (Insel and Fernald, 2004; Maroun and Wagner, 2016). Because long-term SRM formation is dependent on the hippocampus (Kogan et al., 2000) and targeted activation of the CA2 has been shown to enhance SRM (Smith et al., 2016), we sought to evaluate the potential contribution of CA2 OXTRs to long-term SRM formation. To this end, we have taken advantage of Cre/loxP recombinase-based strategy to conditional deletion of Oxtr in excitatory neurons of mouse CA2/CA3a. Using a combination of genetic, behavioral, and electrophysiological strategies, we provide direct evidence for the importance of CA2/CA3a OXTRs in the persistence of long-term SRM.

\section{Materials and Methods}

Animals. Adult male C57BL/6 (10-12 weeks), homozygous Oxtr-floxed $\left(\mathrm{Oxtr}^{\mathrm{J} / \mathrm{J}}\right.$; donating investigator: Dr. W. Scott Young 3rd, National Institute of Mental Health, National Institutes of Health, Bethesda, MD) and calcium/calmodulin-dependent protein kinase II $\alpha$ (CaMKII $\alpha)$-Cre transgenic mice were originally obtained from The Jackson Laboratory and bred in our animal facility. Oxtr ${ }^{\mathrm{J} / \mathrm{J}}$ mice were crossed with CaMKII $\alpha$ Cre mice to generate Oxtr conditional knock-out $\left(\mathrm{Oxtr}^{-/-}\right)$mice on a C57BL/6 genetic background. The heterozygous OXTR-Venus knock-in $\left(O x t r^{\text {Venus }-\mathrm{Neo} /+}\right)$ mice were generated as described previously (Yoshida et al., 2009). Mice were genotyped by a PCR-based method using genomic DNA isolated from tail samples as previously described (Huang et al., 2014). Mice were housed in groups of three under a $12 \mathrm{~h}$ light/dark cycle in a humidity- and temperature-controlled $\left(25 \pm 1^{\circ} \mathrm{C}\right)$ rooms with ad libitum access to food and drinking water and behavioral testing occurred during the light cycle. All experimental procedures were performed according to the National Institutes of Health guidelines for the care and use of laboratory animals and in accordance with protocol approval from the Institutional Animal Care and Use Committee of National Cheng Kung University.

Construction and production of adeno-associated virus. Adeno-associated virus (AAV) plasmids encoding a green fluorescent protein/Cre recombinase (Cre-GFP) fusion protein (plasmid 20781) or a GFP (AAV-GFP; plasmid 49055) were obtained from Addgene. Plasmid DNA was amplified purified and collected using a standard plasmid Maxiprep kit (Qiagen). The purified plasmids were mixed into $\mathrm{CaCl}_{2}$ solution with the DNA plasmid coding AAV capsid DJ serotype and cotransfected into HEK293T cells using calcium phosphate precipitation methods as previously described (Yang et al., 2012). Transfected cells were harvested at $72 \mathrm{~h}$ after transfection and the virus was purified using the AAV purification mega kit (Cell Biolabs). Viral titers were $5 \times 10^{12}$ particles $/ \mathrm{ml}$ and stored in aliquots at $-80^{\circ} \mathrm{C}$ until use.

Stereotaxic viral injection. Recombinant AAV-GFP or AAV-Cre-GFP was injected bilaterally into dorsal CA2 region using standard stereotaxic procedures. Under isoflurane (2-5\%; Attane) anesthesia, concentrated virus-stock solution was injected into the targeted sites $(0.5 \mu \mathrm{l}$ per site at $0.25 \mu \mathrm{l} / \mathrm{min}$ ) by using a Hamilton syringe with a 34 gauge blunted-tip needle. The stereotaxic coordinates used were as follows [measured from bregma (in $\mathrm{mm}$ )]: anteroposterior -2.3 , mediolateral \pm 2.7 , and dorsoventral -2.0 according to the description by Franklin and Paxinos (2008). All injections were performed on 8-week-old mice and were followed by a 3 week viral incubation period before starting the behavioral experiments. At the end of the experiment, mice used in behavioral tests were killed by perfusion and the injection sites were evaluated for each animal. Only those mice with accurate injections in both sides of the CA2 were included for analysis. To determine the OXT-containing projecting fibers from the PVN to the stratum lacunosum-moleculare (SLM) of the CA2, AAV-Ubi-GFP $(0.25 \mu \mathrm{l})$ was bilateral injected in the PVN region [anteroposterior -0.58 , mediolateral \pm 0.2 , dorsoventral -4.75 $(\mathrm{mm})]$. Three weeks later, brain sections were collected and stained with anti-OXT antibody (1:500; Millipore, AB911; RRID:AB_2157629).

Fluorescent in situ hybridization. Fluorescent in situ hybridization (FISH) was performed using RNAscope Multiplex Fluorescent Reagent Kit 2.0 manufacturer's instructions (Advanced Cell Diagnostics; RRID: SCR_012481). Briefly, brain sections $(16 \mu \mathrm{m})$ were fixed in 4\% paraformaldehyde for $15 \mathrm{~min}$ and dehydrated through graded ethanol solutions (50, 70, and $100 \%)$ for $5 \mathrm{~min}$ each. Sections were subjected to reagent Pretreat 3 at $25^{\circ} \mathrm{C}$ for $30 \mathrm{~min}$ and then hybridized with probes at $40^{\circ} \mathrm{C}$ for $2 \mathrm{~h}$ in a humidified oven (ACD HybEZ Hybridization System). The Oxtr-O1 probe (Catalog \#454011) and the CaMKII $\alpha$ probe (Catalog \#445231) were used to target exon 3 of the Oxtr mRNA and CaMKII $\alpha$ mRNA, respectively. After hybridization, brain sections were sequentially applied with a series of probe signal amplification steps, rinsed with ACD Wash Buffer twice for 2 min between each step and mounted with VECTASHIELD antifade mounting medium (Vector Laboratories) containing 4',6-diamidino-2-phenylindole (DAPI; 1:5000; Sigma-Aldrich).

Slice preparations and electrophysiology. Hippocampal slices were prepared as previously described (Yang et al., 2012). In brief, mice were anesthetized with isoflurane and decapitated, and brains were rapidly removed and placed in ice-cold sucrose cutting solution containing the following (in mM): sucrose 234, $\mathrm{KCl} 2.5, \mathrm{CaCl}_{2} 0.5, \mathrm{MgCl}_{2} 7, \mathrm{NaHCO}_{3} 25$, $\mathrm{NaH}_{2} \mathrm{PO}_{4} 1.25$, and glucose 11 at $\mathrm{pH} 7.3-7.4$ and equilibrated with $95 \%$ $\mathrm{O}_{2}-5 \% \mathrm{CO}_{2}$. Slices $(400 \mu \mathrm{m})$ were prepared using a vibrating microtome (VT1200S; Leica) and transferred to a holding chamber of artificial CSF (ACSF) containing the following [(in mM): $\mathrm{NaCl} 117, \mathrm{KCl} 4.7, \mathrm{CaCl}_{2} 2.5$, $\mathrm{MgCl}_{2} 1.2, \mathrm{NaHCO}_{3} 25, \mathrm{NaH}_{2} \mathrm{PO}_{4} 1.2$, and glucose 11 at $\mathrm{pH} 7.3-7.4$ and 
equilibrated with $95 \% \mathrm{O}_{2}-5 \% \mathrm{CO}_{2}$ ] and maintained at room temperature for at least $1 \mathrm{~h}$ before use.

For recording, one slice was transferred to the recording chamber and continually perfused with oxygenated ACSF at a flow rate of $2-3 \mathrm{ml} / \mathrm{min}$ at $32.0 \pm 0.5^{\circ} \mathrm{C}$. The extracellular field potential recordings were performed using an Axoclamp-2B amplifier (Molecular Devices). Microelectrodes were pulled from microfiber-filled $1.0 \mathrm{~mm}$ capillary tubing on a Brown-Flaming electrode puller (Sutter Instruments). The responses were low-pass-filtered at $2 \mathrm{kHz}$, digitally sampled at $10 \mathrm{kHz}$, and analyzed using pCLAMP software v8.0 (Molecular Devices; RRID:SCR_011323). Postsynaptic responses were evoked in CA2 apical dendritic areas by extracellular stimulation of EC inputs in the SLM of the CA1 at $0.033 \mathrm{~Hz}$ with a concentric bipolar stimulation electrode as previously described (Chafai et al., 2012). The stimulation strength was set to elicit response for which the amplitude was $30-40 \%$ of the maximum spike-free response. Field EPSPs (fEPSPs) were recorded with glass pipettes filled with $1 \mathrm{M} \mathrm{NaCl}(2-3 \mathrm{M} \Omega$ resistance) and the fEPSP slope was measured from $\sim 20-70 \%$ of the rising phase using a least-squares regression. Long-term potentiation (LTP) was induced by high-frequency stimulation (HFS), at the test pulse intensity, consisting of one or two $1 \mathrm{~s}$ trains of stimuli separated by an intertrain interval of $20 \mathrm{~s}$ at $100 \mathrm{~Hz}$. Long-term depression (LTD) was induced by low-frequency stimulation (LFS) delivered at $1 \mathrm{~Hz}$ for $15 \mathrm{~min}$ (900 pulses). The magnitudes of LTP and LTD were averaged the responses recorded during the last $10 \mathrm{~min}$ of the recording and normalized to $10 \mathrm{~min}$ of baseline before LTP or LTD induction.

Whole-cell patch-clamp recordings were made from visually identified pyramidal neurons in the CA2 region of hippocampal slices using an Axopatch 200B amplifier (Molecular Devices). CA2 pyramidal neurons were further confirmed by their specific intrinsic membrane properties [e.g., the presence of a delay before the firing of the first spike (see Fig. 6A) and the absence of a slow after-hyperpolarization in response to a sustained depolarization; Chevaleyre and Siegelbaum, 2010]. Data acquisition and analysis were performed using a digitizer (Digidata 1440A) and pCLAMP 9 software (Molecular Devices; RRID:SCR_011323). For measurement of synaptically evoked EPSCs, a concentric bipolar stimulation electrode was placed in the SLM of the CA1 $(\sim 200 \mu \mathrm{m}$ from the CA2) to stimulate EC inputs at $0.05 \mathrm{~Hz}$ and the superfusate routinely contained gabazine ( $10 \mu \mathrm{M}$; Tocris Bioscience) to block $\mathrm{GABA}_{\mathrm{A}}$ receptor-mediated inhibitory synaptic responses. EPSCs were recorded in voltage-clamp mode at the holding potential of $-73 \mathrm{mV}$. The composition of intracellular solution was as follows (in mM): $135 \mathrm{KMeSO}_{4}, 5 \mathrm{KCl}, 10 \mathrm{HEPES}, 0.1$ EGTA-Na, $2 \mathrm{NaCl}, 5 \mathrm{ATP}, 0.4 \mathrm{GTP}$, and 10 phosphocreatine at pH 7.2 and osmolarity 280-290 mosM. Biocytin (0.5\%; Sigma-Aldrich) was routinely included in the intracellular solution to allow post hoc staining of the recorded neurons. During LTP experiments, synaptically-evoked EPSPs were obtained in current-clamp mode at a membrane potential of $-70 \mathrm{mV}$ in the presence of the $\mathrm{GABA}_{\mathrm{A}}$ receptor antagonist gabazine (10 $\mu \mathrm{M}$; Tocris Bioscience) and $\mathrm{GABA}_{\mathrm{B}}$ receptor antagonist CGP55845 (2 $\mu \mathrm{M}$; Tocris Bioscience). IPSCs were performed in voltage-clamp mode with the cell held at $0 \mathrm{mV}$ and in the presence of 6-cyano-7-nitroquinoxaline-2,3-dione (20 $\mu \mathrm{M}$; Tocris Bioscience) and D-2-amino-5phosphonovaleric acid (APV, $50 \mu \mathrm{M}$; Tocris Bioscience) to eliminate glutamate currents with an intracellular solution containing $135 \mathrm{CsMeSO}_{4}$ instead of $\mathrm{KMeSO}_{4}$. LTD of IPSCs were induced by HFS, at the test pulse intensity, consisting of two $1 \mathrm{~s}$ trains of stimuli separated by an intertrain interval of $20 \mathrm{~s}$ at $100 \mathrm{~Hz}$ (Piskorowski and Chevaleyre, 2013). To assess OXT-induced change in synaptic transmission, a highly selective OXTR agonist $\left[\mathrm{Thr}^{4}, \mathrm{Gly}^{7}\right]$-OXT $(0.1 \mu \mathrm{M}$; Sigma-Aldrich) was bath applied for $20 \mathrm{~min}$ and then washed out. Series resistance and input resistance were monitored online throughout the whole-cell recording with a $5 \mathrm{mV}$ depolarizing step given after every afferent stimulus and data were discarded if access resistance changed by $>20 \%$. Sample traces are averages of 10 consecutive sweeps.

Three-chambered social approach assay. The three-chamber tests for sociability, response to social novelty and SRM were performed as previously described (Moy et al., 2004) with minor modifications. The apparatus was a rectangular, three-chambered box fabricated from clear polycarbonate $(60 \times 40 \times 22 \mathrm{~cm})$. Dividing walls had retractable doorways that allowed access into each chamber. The assay consisted of three testing sessions. On day 1 , mice were initially allowed to explore the three chambers freely for $10 \mathrm{~min}$. After the habituation period, a male juvenile mouse (stimulus), which had no prior contact with the subject mice, was placed in a wire cage of left or right chamber (systemically alternated) and an identical empty wire cage was placed in the other chamber. The subject mouse was placed in the middle chamber, and then the mouse was allowed to freely explore all three chambers for $5 \mathrm{~min}$ (sociability test). The time that the test subject spent investigating each chamber was measured. At the end of the $5 \mathrm{~min}$ sociability test, the subject mouse was again gently guided to the center chamber while the empty wire cage was replaced with a novel unfamiliar male juvenile (4-week-old) mouse (Novel 1). The subject mouse again freely explored all three chambers for $5 \mathrm{~min}$ to quantify social preference for a new stranger (social novelty test). The subject mouse had a free choice between the first, already-investigated mouse (familiar) and the novel unfamiliar mouse. The time spent in each chamber was measured. After social novelty test, mice were returned to their home cages. On days 2 or 8, 1 or 7-d long-term SRM was examined in which the familiar mouse was placed in either the left or right chamber, and a novel unfamiliar male juvenile mouse (Novel 2) was placed in the cage of other chamber. The subject mouse again freely explored all three chambers for $5 \mathrm{~min}$. The subject mouse had a free choice between the familiar mouse and the novel unfamiliar mouse for $5 \mathrm{~min}$. The behavior of the animals was videotaped, tracked and analyzed with the behavioral tracking system EthoVision (Noldus; RRID:SCR_000441) under 70 Lux lighting condition.

Five-trial social memory assay. The five-trial social test was performed as previously described (Hitti and Siegelbaum, 2014). In brief, subject mice were individually housed for $7 \mathrm{~d}$ before testing to establish territorial dominance. On the day of testing, a CD-1 ovariectomized female mouse was presented to the subject male mouse's cage for four successive $1 \mathrm{~min}$ trials with a $10 \mathrm{~min}$ intertrial interval. On the fifth trial, a novel CD-1 ovariectomized female mouse was presented and the duration of social investigation was recorded.

Open-field test. For the open-field (OF) test, mice were individually placed in the center of the test chamber and left to freely explore for 10 min under a dimmed illumination $(\sim 10$ Lux $)$. The test chamber consisted of a square ground area $(42 \times 42 \mathrm{~cm})$ surrounded by a $42-\mathrm{cm}$-high wall set on a nonreflective white plastic base. The behavior of the animals was videotaped, tracked, and analyzed with the behavioral tracking system EthoVision. The activity was evaluated based on time spent in the center zone and total distance traveled in the OF. The chamber was thoroughly cleaned with $70 \%$ ethanol after each trial. The percentage of time spent in the center zone is defined as the percentage of time for the animals exploring the center $25 \%(21 \times 21 \mathrm{~cm})$ of the chamber.

Elevated plus maze. The elevated plus maze (EPM) test was performed as previously described (Pellow et al., 1985). The plus-cross-shaped maze was custom-made of black Plexiglas consisting of two open arms $(25 \times$ $5 \times 0.5 \mathrm{~cm})$ and two enclosed arms $(25 \times 5 \times 16 \mathrm{~cm})$ extending from a central square platform $(5 \times 5 \mathrm{~cm})$ mounted on a wooden base raised 50 $\mathrm{cm}$ above the floor. Animals were placed on the center square platform facing an open arm and allowed to freely explore the maze for $5 \mathrm{~min}$. The apparatus was illuminated with dimmed light ( $\sim 10$ Lux). The behavior of the animals was videotaped, tracked, and analyzed with the behavioral tracking system EthoVision. The activity was evaluated based on the percentage of time spent in the open versus closed arms. The apparatus was thoroughly cleaned with $70 \%$ ethanol after each trial.

Novelty-suppressed feeding. The novelty suppressed feeding (NSF) test was performed as previously described (Gross et al., 2002). In brief, food was removed from the home cage $24 \mathrm{~h}$ before testing, whereas water remained available ad libitum. The next day, mice were placed at the edge of an OF $(42 \times 42 \mathrm{~cm})$ with a small piece of chow in the center for $10 \mathrm{~min}$. The behavior of the animals was videotaped and analyzed with the behavioral tracking system EthoVision and the latency to begin chewing food was measured.

Histology and quantification. Mice were deeply anesthetized with sodium pentobarbital ( $150 \mathrm{mg} / \mathrm{kg}$, i.p.; Sigma-Aldrich) and transcardially perfused with $4 \%$ paraformaldehyde (PFA; Sigma-Aldrich) in 0.1 м PBS, $\mathrm{pH}$ 7.4. After the perfusion, brains were removed and continue to fix in $4 \%$ PFA for $24 \mathrm{~h}$ at $4^{\circ} \mathrm{C}$ and then transferred to the solution containing 
A
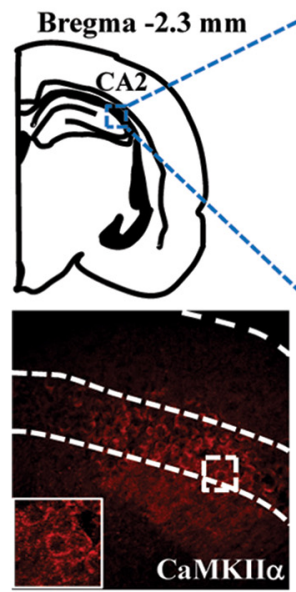

B

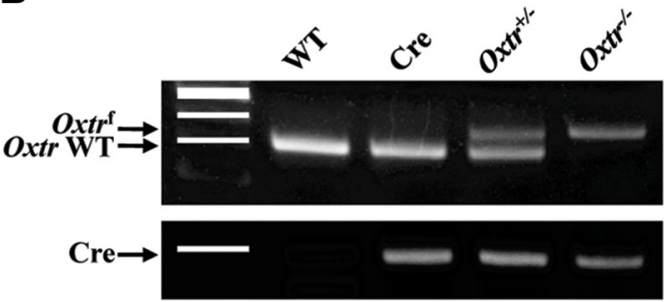

C
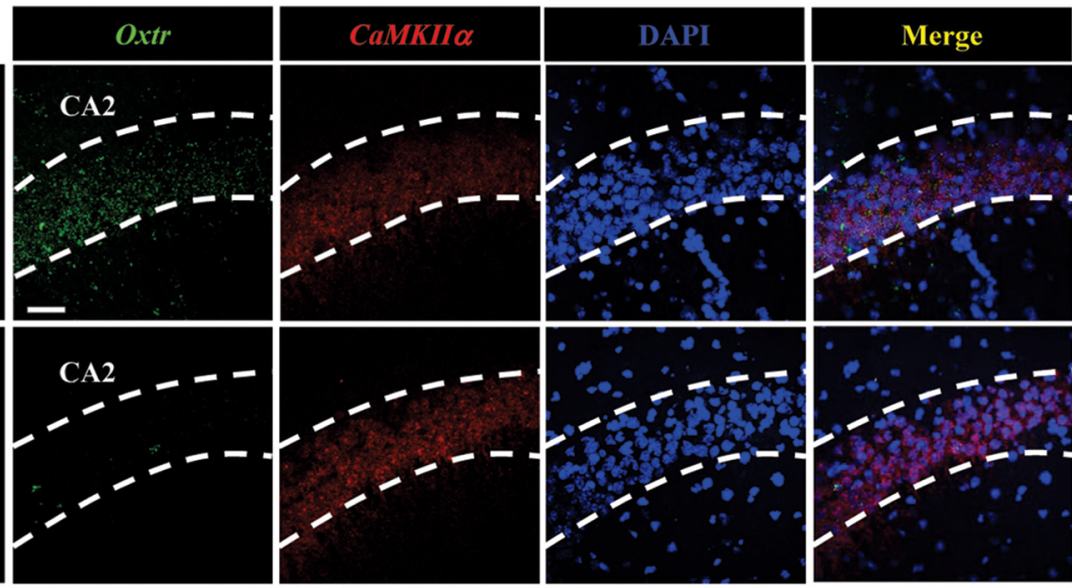

D
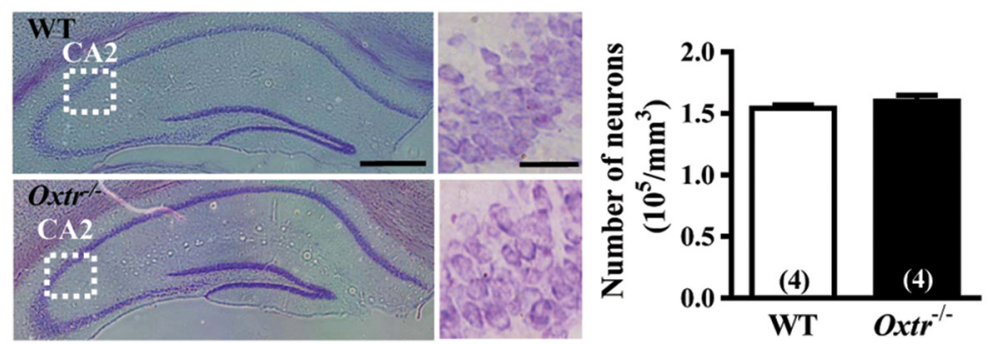

Figure 1. Conditional deletion of Oxtr in CA2 excitatory neurons of the mouse hippocampus. $A$, Doubled-labeled confocal immunofluorescent images showing the colocalization of OXTRs (green) and CaMKII $\alpha$ (red) in the CA2 of the mouse hippocampus. Insets, High magnification of the boxed area. Scale bar, $10 \mu \mathrm{m}$. S0, Stratum oriens; SP, stratum pyramidale; SR, stratum radiatum. B, PCR screening of tail-derived genomic DNA for selection of $0 x t^{-1-}$ mice. C, Dual-probe FISH images showing the expression of Oxtr mRNA and CaMKII $\alpha$ mRNA in the CA2 of WT and Oxtr ${ }^{-1-}$ mice (counterstained with DAPI, blue). Scale bar, $50 \mu \mathrm{m}$. Data were replicated in four mice. D, Representative photographs with cresyl violet staining of the CA2 showing that the number of pyramidal neurons was not significantly affected by conditional deletion of $0 x$ tr compared with age-matched WT mice. Group data showing the summary results from four mice of each group at 10 weeks old. Scale bars: left, $10 \mu \mathrm{m}$; right, $200 \mu \mathrm{m}$. The total number of animal examined is indicated by $n$ in parenthesis. Data represent the mean \pm standard error of the mean (SEM).

$30 \%$ sucrose that immersed in $4^{\circ} \mathrm{C}$ for at least $48 \mathrm{~h}$ before slicing. Coronal brain slices containing the hippocampus were sectioned to a $20 \mu \mathrm{m}$ thickness, washed with $0.3 \%$ Triton X-100, and then incubated for blocking with solution containing 3\% goat serum in PBS. For quantitative evaluation of neuronal numbers with Nissl staining, sections were mounted directly on gelatin-coated glass slides and dried. The slides were stained with $1.0 \%$ cresyl violet, dehydrated through a series of ethanol, cleared, and coverslipped with Permount (Fisher Scientific). Nissl staining within the CA2 region was quantified in images from $\sim 1.5-2.5 \mathrm{~mm}$ posterior to bregma every sixth coronal section captured at $200 \times$ magnification and digitized with an Olympus BX51 microscope coupled to an Olympus DP70 digital camera. All images were imported into NIH ImageJ software for analysis.

Quantitative real-time PCR. Total RNA was isolated from hippocampal CA1, CA2, and CA3 tissue lysates using a Tri Reagent kit (Molecular Research Center) and treated with RNase-free DNase (RQ1, Promega) to remove potential contamination by genomic DNA as previously described (Lin et al., 2017). Total RNA ( $2 \mu \mathrm{g}$ ) from samples was reverse transcribed using a SuperScript cDNA synthesis kit (Invitrogen). Quantitative real-time PCR (qRT-PCR) was performed on the Roche LightCycler instrument (Roche Diagnostics: RRID:SCR_001326) using the FastStart DNA Master SYBR Green I kit (Roche Applied Science) according to the manufacturer's instructions. The primers used in this experiment for Oxtr were as follows: forward (5'-TTCTTCGTGCAGATGTG GAG-3') and reverse (5'-CCTTCAGGTACCGAGCAGAG-3'). The PCRs were run for 40 cycles. Each amplification cycle included denaturation at $95^{\circ} \mathrm{C}$ for $20 \mathrm{~s}$, annealing at $58^{\circ} \mathrm{C}$ for $20 \mathrm{~s}$, and extension at $72^{\circ} \mathrm{C}$ for $40 \mathrm{~s}$. All reactions were repeated in duplicate and data were analyzed by LightCycler quantification software to determine the threshold cycle above background for each reaction. The relative transcript amount of the gene of interest, which was calculated using standard curves of serial RNA dilutions, was normalized to $\beta$-actin rRNA.

Golgi impregnation. Mice were deeply anesthetized with sodium pentobarbital $(150 \mathrm{mg} / \mathrm{kg})$ and transcardially perfused with $0.1 \mathrm{M} \mathrm{PBS}$ and then brains were removed and immersed in Golgi-Cox solution at room temperature for 2 weeks. After transferred to a $30 \%$ sucrose solution for $48 \mathrm{~h}, 200-\mu \mathrm{m}$-thick coronal sections were prepared by use of a vibrating microtome (VT1200S). The slices were subsequently alkalinized in $18.7 \%$ ammonia, fixed in Kodak Rapid Fix solution, dehydrated in alcohol, cleared with xylene, mounted onto gelatinized slides, and coverslipped under Permount (Fisher Scientific). Protrusion number was determined blind to the treatment condition. At least five pyramidal neurons from each animal ( 5 animals per group) were chosen for analysis. Images of dendritic protrusions were taken from the secondary branches of the apical dendrites (30-80 $\mu \mathrm{m}$ from the soma) of CA2 pyramidal neurons by using the Olympus microscope equipped with a $100 \times 1.25$ NA oil-immersion objective. Multiple $Z$-stack images of neurons from the CA2 region were collected with the aid of a computerassisted neuron tracing system (Neurolucida; MicroBrightField; RRID: SCR_001775) and further reconstructed by using ImageJ software. The numbers of protrusions were counted with $30 \mu \mathrm{m}$ dendrite segments and presented as the number of dendritic protrusions in $30 \mu \mathrm{m}$. According to their morphology, protrusions were distinguished into four categories: (1) mushroom-shaped spines with a short neck, (2) stubby spines with a head but without a neck, (3) thin spines with a long neck and small heads, and (4) filopodia with no detectable head as described previously (Tyler and Pozzo-Miller, 2003; Wang et al., 2017).

Immunofluorescence. Oxtr Venus-Neo/+ mice were deeply anesthetized with sodium pentobarbital $(150 \mathrm{mg} / \mathrm{kg})$ and transcardially perfused with $4 \%$ PFA in $0.1 \mathrm{M}$ PBS, pH 7.4. After the perfusion, brains and spinal cord 
A
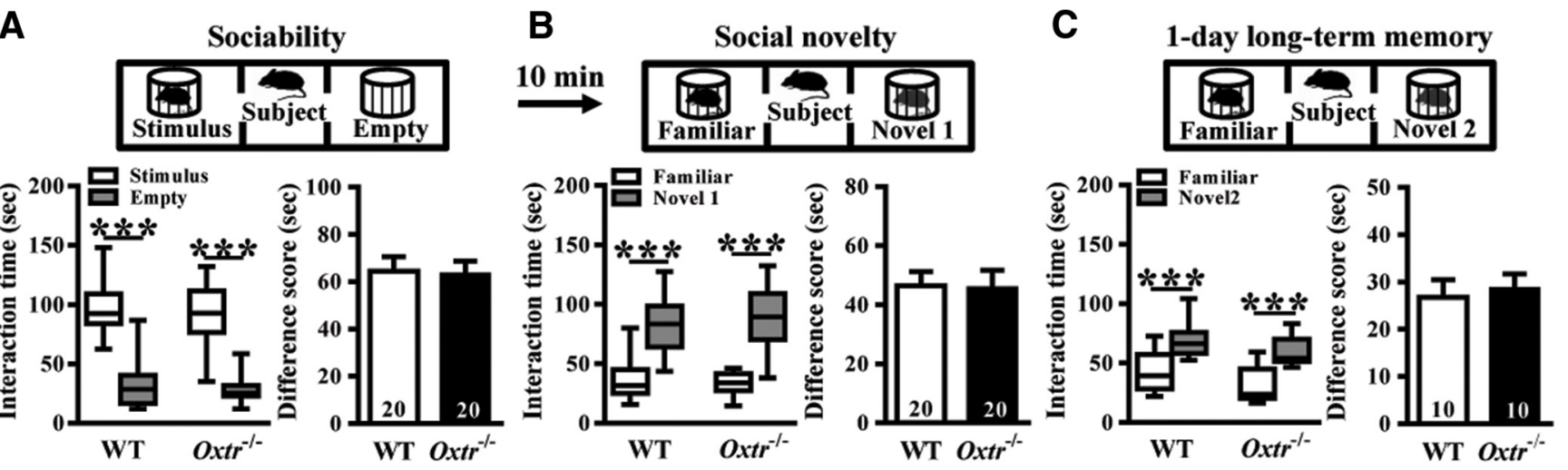

D 7-day long-term memory

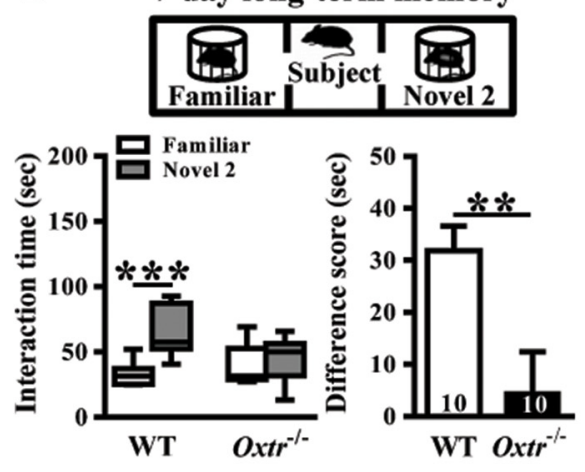

E

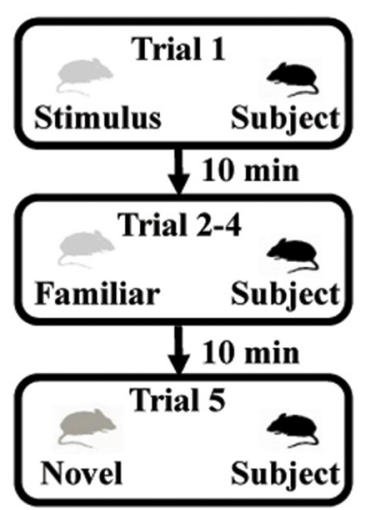

\section{5-trial social memory assay}

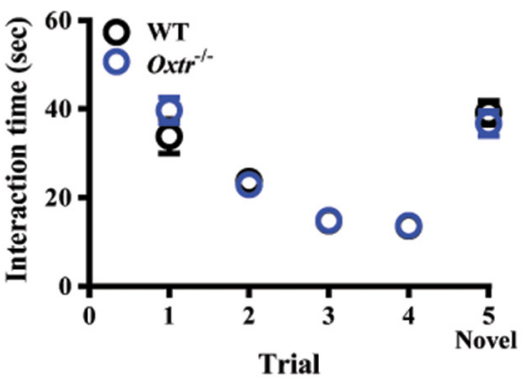

Figure 2. Conditional deletion of Oxtr in forebrain excitatory neurons leads to impair the persistence of long-term SRM. $\boldsymbol{A}$, Top, Schematic diagram of the three-chamber sociability test. Bottom left, Time spent in each side chamber containing the juvenile stimulus mouse or empty wire cage. Both WT and $0 x t^{-/-}$subject mice spent significantly more time interacting with the cage containing the juvenile stimulus mouse than with the empty wire cage. Bottom right, difference scores (stimulus minus empty) were similar between WT and $0 x$ tr $^{-1-}$ mice in the sociability test. B, Top, Schematic diagram of the three-chamber social novelty test. Bottom left, Time spent in each side chamber containing a familiar mouse or a Novel 1 mouse, 10 min after the first exposure. Both WT and $0 \mathrm{xtr}^{-1-}$ subject mice spent significantly more time interacting with the cage containing the novel mouse than with the familiar mouse. Bottom right, Difference scores (Novel 1 minus familiar) were similar between WT and Oxtr ${ }^{-1-}$ mice in the social novelty test. $C$, Top, Schematic diagram of the three-chamber long-term SRM test. Bottom left, Time spent in each side chamber containing a familiar mouse or a Novel 2 mouse, $1 \mathrm{~d}$ after the exposure. Both WT and $\mathrm{Oxtr}^{-1-}$ subject mice spent significantly more time interacting with the cage containing the novel mouse than with the familiar mouse. Bottom right, Difference scores (Novel 2 minus familiar) were similar between WT and $0 x t^{-1-}$ mice in 1-d long-term SRM test. D, Top, Schematic diagram of the three-chamber long-term SRM test. Bottom, Time spent in each side chamber containing a familiar mouse or a Novel 2 mouse, $7 \mathrm{~d}$ after the exposure. WT, but not $0 x t^{-1-}$, subject mice spent significantly more time interacting with the cage containing the novel mouse than with the familiar mouse. Bottom right, Difference score (Novel 3 minus familiar) of Oxtr ${ }^{-1-}$ mice was significantly less than that of WT mice in 7-d long-term SRM test. $\boldsymbol{E}$, Left, Schematic diagram of the 5-trial social memory assay. Right, Both WT and Oxtr ${ }^{-1-}$ subject mice showed a similar decline in the investigation time over trials one to four when they were repetitively presented the familiar ovariectomized female CD-1 mouse and increased in the investigation time on Trial 5 when they were presented with a novel ovariectomized female CD-1 mouse. The total number of animal examined is indicated by $n$ in parenthesis. Data represent the mean \pm SEM. ${ }^{* *} p<0.01$, ${ }^{* * *} p<0.001$.

were removed and continue to fix in $4 \%$ PFA for $24 \mathrm{~h}$ at $4^{\circ} \mathrm{C}$ and then transferred to the solution containing $30 \%$ sucrose that immersed in $4^{\circ} \mathrm{C}$ for at least $48 \mathrm{~h}$ before slicing. Coronal slices were sectioned to a $40 \mu \mathrm{m}$ thickness, washed with $0.3 \%$ Triton X-100, and then incubated for blocking with solution containing 3\% goat serum in PBS. After blocking, the sections were incubated with primary antibodies against CaMKII $\alpha$ (1: 500; Novas Biologicals, NB100-81830; RRID:AB_1145020) or striatumenriched protein-tyrosine phosphatase (STEP; also known as PTPN5, 1:500; Cell Signaling Technology, Catalog \#4376; RRID:AB_1904101). Finally, sections were washed with TBS-T (10 mM Tris-HCl, $150 \mathrm{~mm}$ $\mathrm{NaCl}$, and $0.025 \%$ Tween 20 , pH 7.4) and then incubated with the secondary AlexaFluor 568 antibody (Life Technologies) for $2 \mathrm{~h}$ at room temperature in blocking buffer. The immunostained sections were collected on separate gelatin-subbed glass slides, rinsed extensively in PBS, and mounted with ProLong Gold Antifade Reagent (Invitrogen). Fluorescence images of neurons were obtained using an Olympus FluoView FV1000 confocal microscope. All images were imported into NIH ImageJ software for analysis.

\section{Experimental design and statistical analysis}

Experiment 1: conditional deletion of Oxtr from CA2 pyramidal neurons. To examine the expression of OXTRs in hippocampal CA2 region, we used Oxtr Venus-Neo/+ mice, which express the Venus variant of yellow fluorescent protein in OXTR-expressing cells $(n=4$; Fig. $1 A)$. We used the Cre-loxP recombination approach to conditionally delete Oxtr from hippocampal excitatory neurons by crossing mice expressing CaMKII $\alpha$ Cre with Oxtr ${ }^{\mathrm{f} / \mathrm{f}}$ mice. PCR and dual-probe FISH were used to confirm the efficiency of Cre-loxP-mediated deletion of Oxtr mRNA from CaMKII $\alpha$ mRNA-expressing CA2 pyramidal neurons $(n=4$ mice in each group; Fig. $1 B, C)$. Cresyl violet staining was used to examine whether the total number of CA2 pyramidal neurons was altered by conditional deletion of $\operatorname{Oxtr}(n=4$ mice in each group; Fig. $1 D)$.

Experiments 2 and 3: conditional deletion of CA2/CA3a Oxtr impairs the persistence of long-term SRM. To assess the role of CA2/CA3a OXTRs in social behavior, we compared the performance of WT and Oxtr ${ }^{-1-}$ mice in a three-chamber test for sociability $(n=20$ mice in each group; Fig. $2 A$ ), preference for social novelty ( $n=20$ mice in each group; Fig. $2 B$ ), 1 -d long-term SRM ( $n=10$ mice in each group; Fig. $2 C)$ and 7-d long-term SRM ( $n=10$ mice in each group; Fig. $2 D)$. We also conducted a more stringent five-trial social memory assay to examine the contribution of CA2/CA3a Oxtr to SRM (WT: $n=9$; Oxtr ${ }^{-1-}: n=7$; Fig. 2E). The detailed information can be found in Results describing Figure 2. 
A

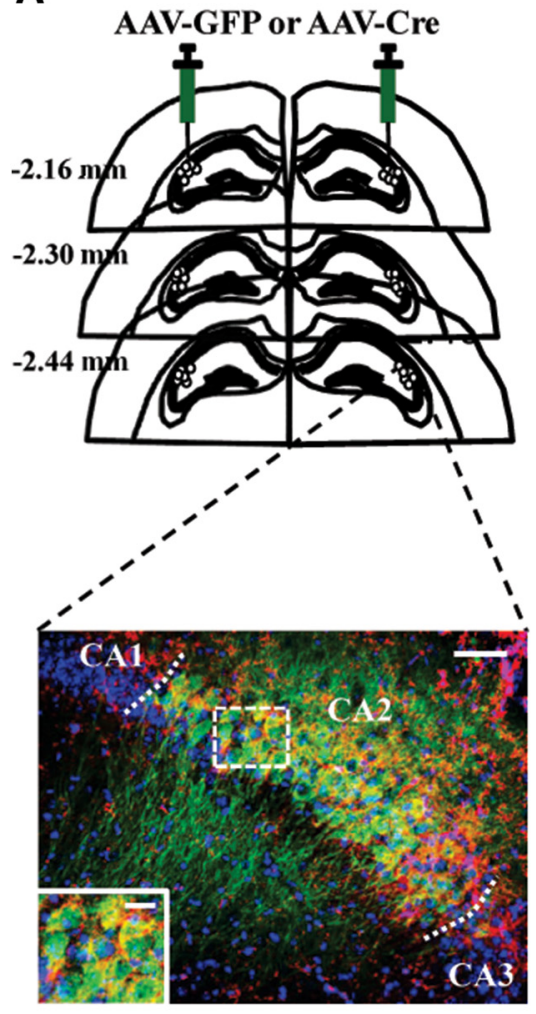

B
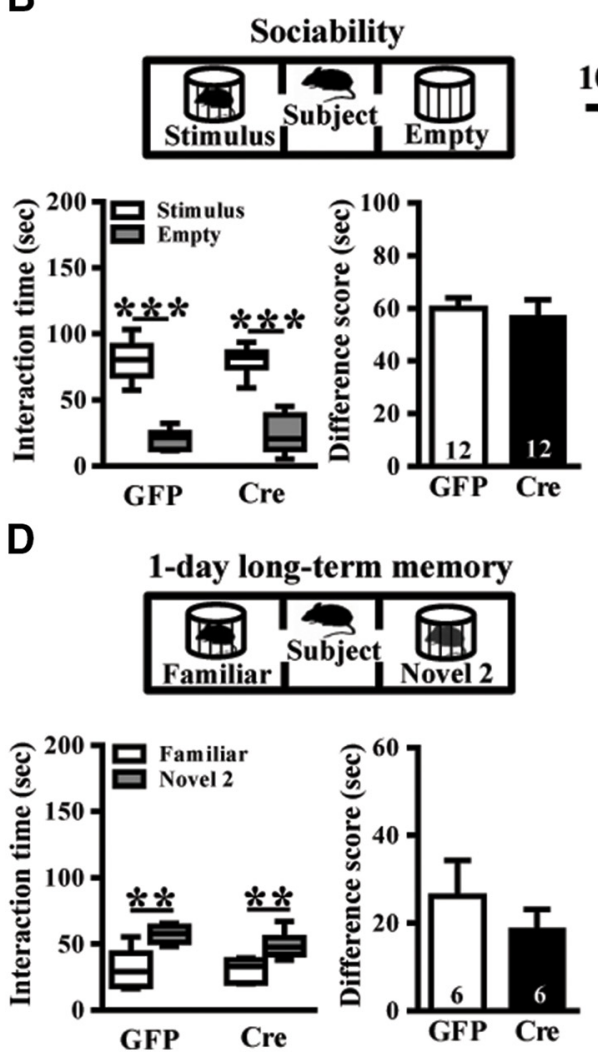

C
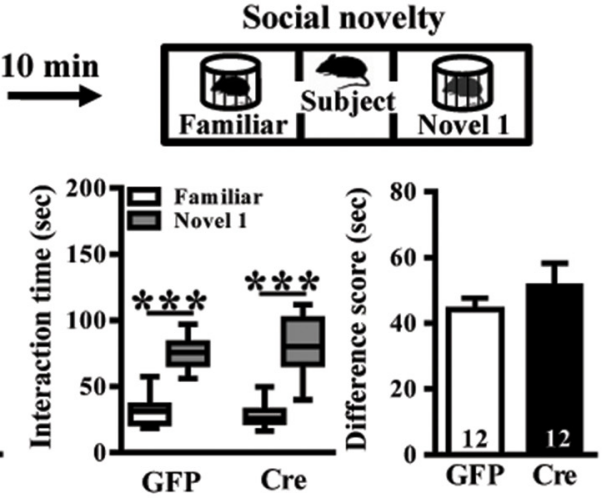

$\mathbf{E}$
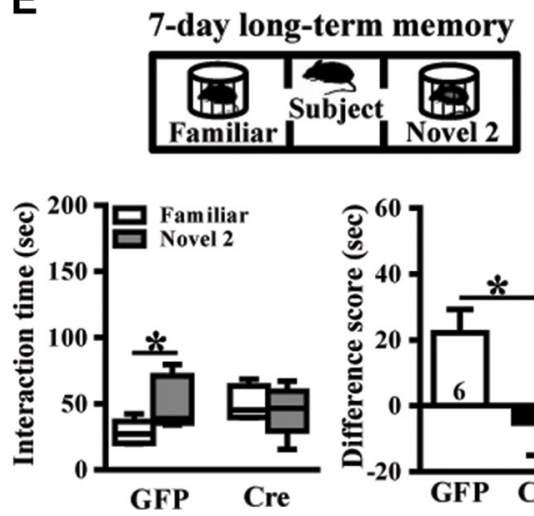

Figure 3. Conditional deletion of CA2/CA3a Oxtr impairs the persistence of long-term SRM. $A$, Top, Schematic illustration of coronal sections illustrating the microinjection sites in the bilateral CA2. Bottom, Representative photograph showing the expression of AAV-Cre-GFP (green) in the CA2 and immunolabeled with STEP (red) and DAPI (blue). Scale bar, $50 \mu \mathrm{m}$. The inset represents high magnification of the boxed area. Scale bar, $20 \mu \mathrm{m}$. B, Top, Schematic diagram of the three-chamber sociability test. Bottom left, Time spent in each side chamber containing the juvenile stimulus mouse or empty wire cage. Both AAV-GFP- and AAV-Cre-GFP-treated subject mice spent significantly more time interacting with the cage containing the juvenile stimulus mouse than with the empty wire cage. Bottom right, Difference scores (stimulus minus empty) were similar between AAV-GFP and AAV-Cre-GFP mice in sociability test. C, Top, Schematic diagram of the three-chamber social novelty test. Bottom, Time spent in each side chamber containing a familiar mouse or a Novel 1 mouse, 10 min after the first exposure. Both AAV-GFP- and AAV-Cre-GFP-treated subject mice spent significantly more time interacting with the cage containing the novel mouse than with the familiar mouse. Bottom right, Difference scores (Novel 1 minus familiar) were similar between AAV-GFP and AAV-Cre-GFP mice in social novelty test. D, Top, Schematic diagram of the three-chamber long-term SRM test. Bottom, Time spent in each side chamber containing a familiar mouse or a Novel 2 mouse, $1 \mathrm{~d}$ after the exposure. Both AAV-GFP- and AAV-Cre-GFP-treated subject mice spent significantly more time interacting with the cage containing the novel mouse than with the familiar mouse. Bottom right, Difference scores (Novel 2 minus familiar) were similar between AAV-GFP and AAV-Cre-GFP mice in 1-d long-term SRM test. $\boldsymbol{E}$, Top, Schematic diagram of the three-chamber long-term SRM test. Bottom, Time spent in each side chamber containing a familiar mouse or a Novel 2 mouse, $7 \mathrm{~d}$ after the exposure. AAV-GFP-, but not AAV-Cre-GFP-treated, subject mice spent significantly more time interacting with the cage containing the novel mouse than with the familiar mouse. Bottom right, Difference score (Novel 3 minus familiar) of AAV-Cre-GFP mice was significantly less than that of AAV-GFP mice in 7-d long-term SRM test. The total number of animal examined is indicated by $n$ in parenthesis. Data represent the mean \pm SEM. ${ }^{*} p<0.05$, ${ }^{* *} p<0.01,{ }^{* * *} p<0.001$.

For Experiment 3, we used Oxtr ${ }^{\mathrm{f} / \mathrm{f}}$ mice in combination with Cre recombinase-mediated gene deletion in a localized fashion through bilateral stereotaxic injections of AAV-GFP or AAV-Cre-GFP adenoviral vectors targeting the CA2, under control of the CaMKII $\alpha$ promoter. The successful transduction of AAV-Cre-GFP or AAV-GFP was confirmed by costaining for the CA2-specific marker STEP (Fig. 3A). We compared the performance of AAV-GFP and AAV-Cre-GFP mice in a three-chamber test for sociability ( $n=12$ mice in each group; Fig. $3 B$ ), preference for social novelty ( $n=12$ mice in each group; Fig. $3 C), 1$-d long-term SRM $(n=6$ mice in each group; Fig. $3 D)$ and 7-d long-term SRM $(n=6$ mice in each group; Fig. 3E). The detailed information can be found in Results describing Figure 3.

Experiments 4: anxiety-like behavior was not affected by conditional deletion of CA2/CA3a Oxtr. We examined whether conditional deletion of CA2/CA3a Oxtr may alter anxiety-like behavior. Oxtr ${ }^{\mathrm{f} / \mathrm{f}}$ mice received bilateral injection of AAV-GFP or AAV-Cre-GFP into the hippocampal CA2 region. Three weeks after stereotaxic injection of AAV-GFP or AAVCre-GFP, mice were subjected to behavioral test. Three behavioral paradigms, including the OF, EPM, and NSF tests were used to evaluate changes in anxiety-like behavior ( $n=10$ mice in each group; Fig. $4 A-E)$.
qRT-PCR analysis confirmed the loss of Oxtr mRNA expression in the CA1, CA2, and CA3 regions 3 weeks after the stereotactic injection of AAV-GFP or AAV-Cre-GFP ( $n=10$ mice in each group; Fig. $4 F)$.

Experiments 5, 6, and 7: conditional deletion of CA2 Oxtr impairs LTP. For Experiment 5, we examined whether the induction of LTP and LTD in the CA2 was affected in $\mathrm{Oxtr}^{-1-}$ mice (Fig. 5A). LTP was induced by HFS, consisting of one (WT: $n=7$; xtr $^{-1-}: n=9$; Fig. $5 B, D)$ or two $1 \mathrm{~s}$ trains of stimuli separated by an intertrain interval of $20 \mathrm{~s}$ at $100 \mathrm{~Hz}$ (WT: $n=6$; Oxtr ${ }^{-1-}: n=9$; Fig. 5C,D) and LTD was induced by LFS delivered at $1 \mathrm{~Hz}$ for $15 \mathrm{~min}$ (WT: $n=5 ; \mathrm{Oxtr}^{-1-}: n=$ 6; Fig. $5 E, F)$ at the synapses between the entorhinal cortex and CA2 pyramidal neurons.

For Experiment 6, we examined whether OXT is directly involved in the regulation of synaptic transmission in the CA2. EPSCs were evoked in CA2 pyramidal neurons in response to stimulation of EC inputs (Fig. $6 A, B)$. We also used NMDA receptor (NMDAR) antagonist APV $(50 \mu \mathrm{M})$ and CaMKII inhibitor KN93 ( $1 \mu \mathrm{M}$; Tocris Bioscience) to confirm that $\left[\mathrm{Thr}^{4}, \mathrm{Gly}^{7}\right]$-OXT-induced synaptic potentiation in CA2 pyramidal neurons relied on NMDAR activation and CaMKII activity (WT: $n=8$; Oxtr ${ }^{-1-}: n=8$; KN93: $n=6$ naive mice; KN92: $n=6$ naive mice; APV: $n=6$ naive mice; Fig. $6 C, D)$. 
A
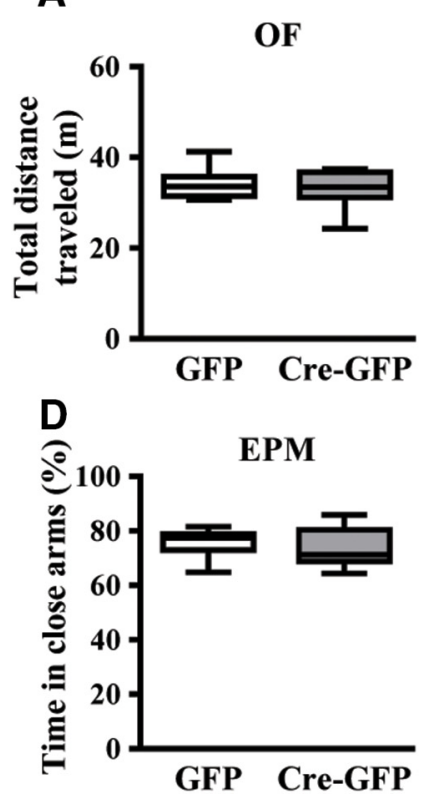

B

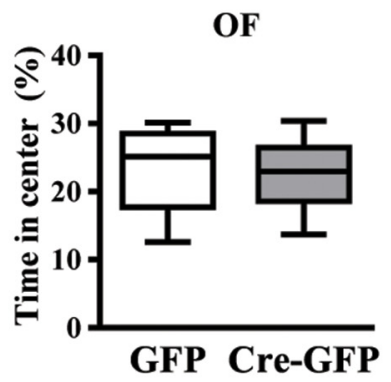

E

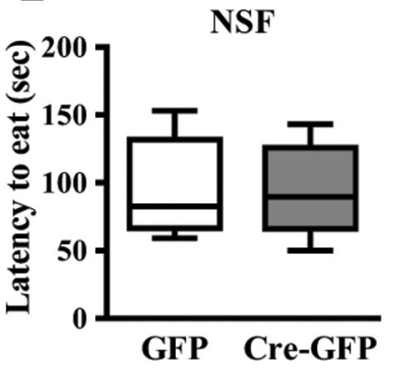

C
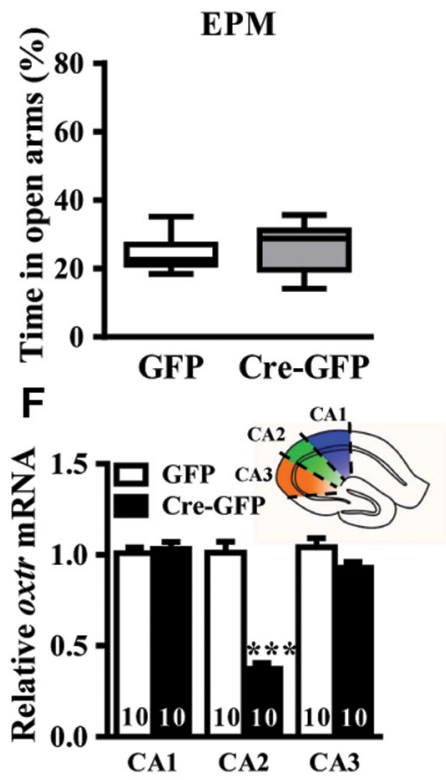

Figure 4. CA2/CA3a Oxtr deletion does not affect anxiety-like behavior. $A, B$, Bar graph comparing the performance of AAV-GFP- and AAV-Cre-GFP-treated mice on the total distance traveled ( $A$ ) and the time spent in the center $(\boldsymbol{B})$ in the $\mathrm{OF}$ test (open field $[\mathrm{OF}]) . \boldsymbol{C}, \boldsymbol{D}$, Bar graph comparing the performance of AAV-GFP- and AAV-Cre-GFP-treated mice on the percentage of time spent in the open $(\boldsymbol{C})$ and closed arms $(\boldsymbol{D})$ in the elevated plus maze (EPM) test. $\boldsymbol{E}$, Bar graph comparing the performance of AAV-GFP- and AAV-Cre-GFP-treated mice on the latency to eat in the novelty suppressed feeding (NSF) test. $\boldsymbol{F}$, Inset, Schematic of a hippocampal slice depicting the CA1, CA2, and CA3 hippocampal regions dissected for Oxtr mRNA analysis. Summary bar graphs showing qRT-PCR of Oxtr mRNA in the CA1, CA2, and CA3 regions from AAV-GFP- and AAV-Cre-GFP-treated mice. Data represent the mean \pm SEM. ${ }^{* * *} p<0.001$.
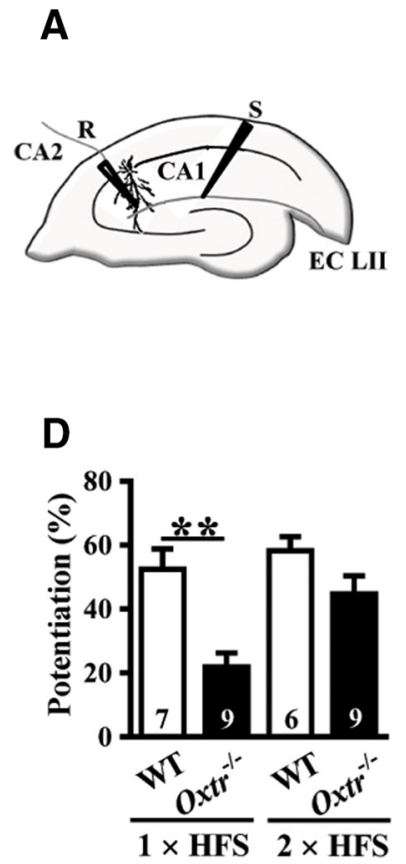

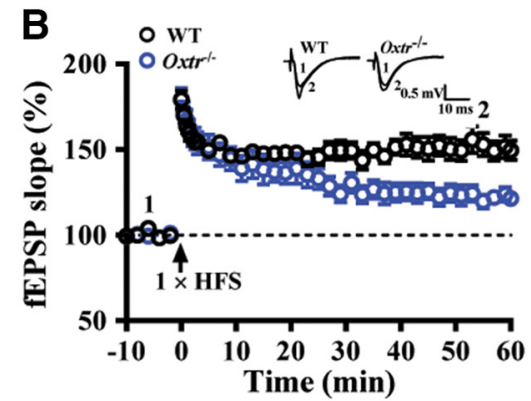

E

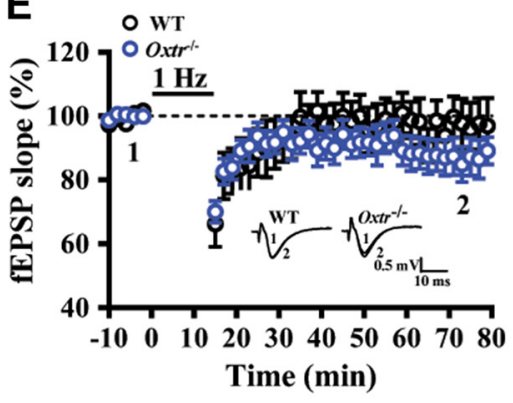

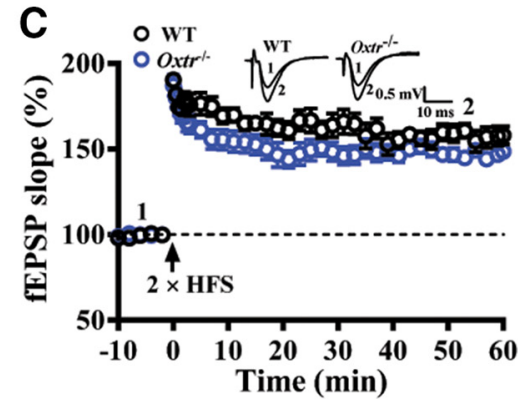

$\mathbf{F}$

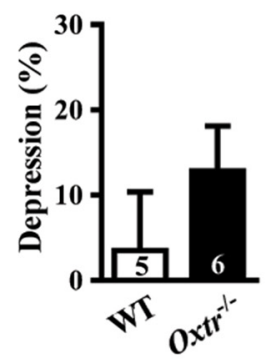

Figure 5. Conditional deletion of CA2/CA3a Oxtr impairs the induction of LTP at $E C \rightarrow C A 2$ synapses. $A$, Schematic of experimental setup showing stimulation electrode placed in the SLM to stimulate EC inputs and field-potential recording electrode placed in the CA2 distal apical dendritic fields. B, Summary of experiments showing one train of $1 \mathrm{~s} \mathrm{HFS} \mathrm{at} 100 \mathrm{~Hz}$ induced LTP of fEPSPs at EC $\rightarrow$ CA2 synapses in slices from WT and Oxtr ${ }^{-1-}$ mice. C, Summary of experiments showing two trains of $1 \mathrm{~s} \mathrm{HFS} \mathrm{at} 100 \mathrm{~Hz}$ induced LTP of fEPSPs at EC $\rightarrow$ CA2 synapses in slices from WT and $\mathrm{Oxtr}^{-I-}$ mice. D, Summary bar graphs depicting levels of potentiation measured $50-60$ min after one- or two-train of HFS at EC $\rightarrow$ CA2 synapses in slices from WT and Oxtr ${ }^{-I-}$ mice. E, Summary graphs of LTD induced with a prolonged LFS ( 900 stimuli delivered at $1 \mathrm{~Hz})$ at $E C \rightarrow C$ A2 synapses in slices from WT and $0 x{ }^{-1-}$ mice. F, Summary bar graphs depicting levels of depression measured $50-60$ min after LFS at $E C \rightarrow$ CA2 synapses in slices from WT and $0 x t^{-1-}$ mice. Representative traces of fEPSPs were taken at the time indicated by number. Dashed lines show level of baseline. The total number of animals examined is indicated by $n$ in parenthesis. Data are represented as mean \pm SEM. ${ }^{* *} p<0.01$.

For Experiment 7, we repeated LTP experiments by performing whole-cell current-clamp recordings of CA2 pyramidal neurons $(n=5$ mice in each group; Fig. 7A). We also determined the effects of the selective OXTR antagonist L-371257 $(1 \mu \mathrm{M})$ on basal EPSC amplitude
( $n=4$ naive mice; Fig. $7 B)$ and LTP induced by a single HFS train at EC $\rightarrow$ CA2 synapses $(n=4$ naive mice; Fig. $7 C)$. We tested the effect of $\left[\mathrm{Thr}^{4}, \mathrm{Gly}^{7}\right]$-OXT $(0.1 \mu \mathrm{M})$ on synaptically evoked IPSCs of CA2 pyramidal neurons $(n=4$ mice in each group; Fig. $7 D)$. We also compared 
A
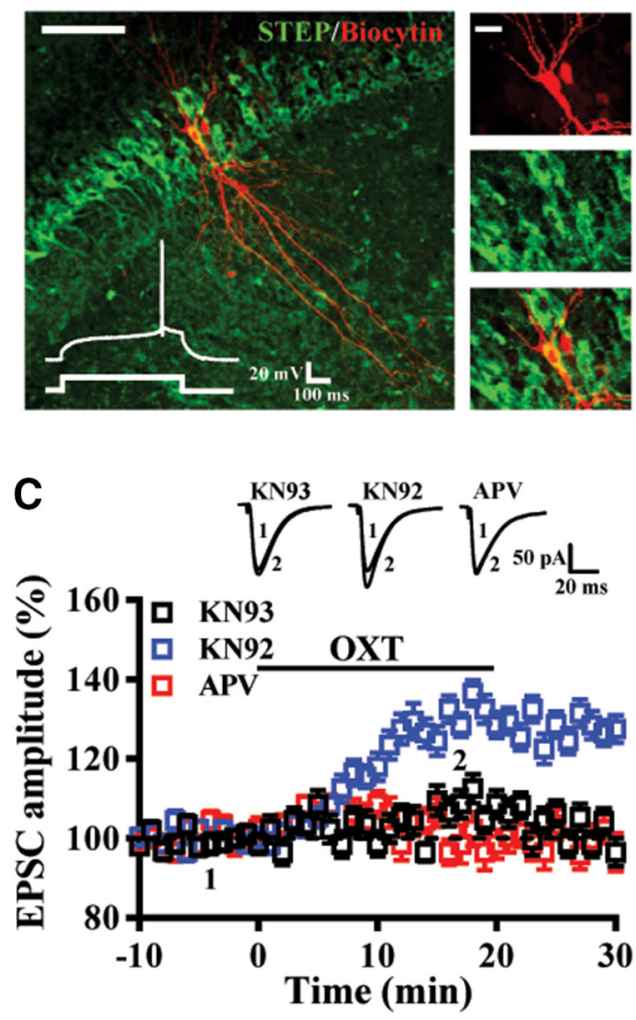

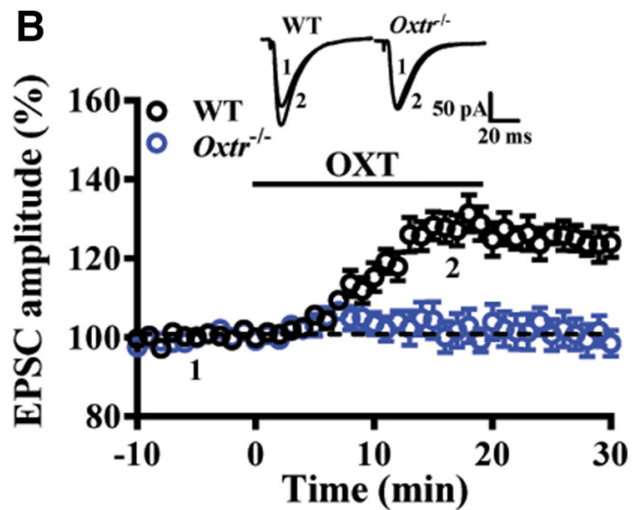

D

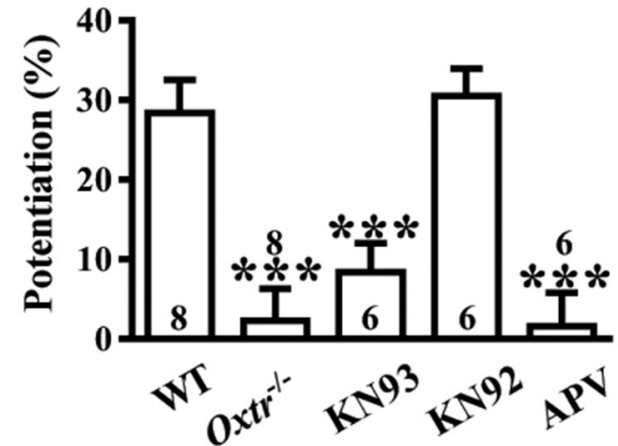

Figure 6. The selective OXTR agonist $\left[\mathrm{Thr}^{4}, \mathrm{Gly}{ }^{7}\right]-0 \mathrm{XT}$ induces a synaptic potentiation at $\mathrm{EC} \rightarrow$ CA2 synapses. A, Left, Representative confocal image of a biocytin-stained CA2 pyramidal cell. Scale bar, $100 \mu \mathrm{m}$. Right, Single confocal attacks showing colocalization of biocytin (red) and STEP (green). Scale bar, $20 \mu \mathrm{m}$. Inset, Whole-cell patch-clamp recording from a CA2 pyramidal cell in current-clamp mode showing the response to a positive step current injection (100 pA, $500 \mathrm{~ms})$. Note that the late-onset firing was initiated by a slow depolarizing ramp. $\boldsymbol{B}$, Bath application of

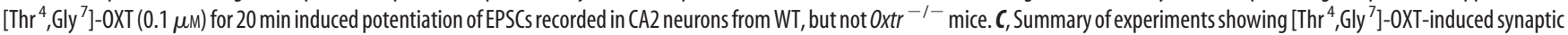
potentiation was blocked by pretreatment of the hippocampal slices with the NMDAR antagonist APV (50 $\mu \mathrm{M}$ ) or the broad spectrum CaMKII inhibitor KN93 (1 $\mu \mathrm{M})$, but not by not its inactive structural analog KN92 (1 $\mu \mathrm{M})$. D, Summary bar graphs depicting levels of potentiation measured 20 min after $\left[\mathrm{Thr}^{4}{ }^{4}, \mathrm{Gly}{ }^{7}\right]-0 \mathrm{XT}$ treatment at EC $\rightarrow$ CA2 synapses in slices from different pretreatments. Representative traces of EPSCs were taken at the time indicated by number. Dashed lines show level of baseline. The total number of animals examined is indicated by $n$ in parenthesis. Data are represented as mean \pm SEM. ${ }^{* *} p<0.001$.

the magnitude of LTD of IPSCs induced by two trains of $100 \mathrm{~Hz}$ HFS delivered $20 \mathrm{~s}$ apart $(n=5$ mice in each group; Fig. $7 E)$. We injected AAV-Ubi-GFP into the PVN to confirm that OXT-containing fibers locate in the CA2 $(n=4$ naive mice; Fig. $7 F)$.

Experiments 8: conditional deletion of Oxtr alters dendritic morphology of CA2 pyramidal neurons. To examine whether conditional deletion of Oxtr may alter dendritic geometry and spine density, we used Golgi-Cox staining to visualize individual CA2 pyramidal neurons in WT and $O x t r^{-1-}$ mice and analyzed the complexity of their dendritic trees $(n=5$ mice in each group; Fig. $8 A-C$ ). The density of dendritic spine was detected on secondary and tertiary branches of apical dendrites of CA2 pyramidal neurons $(n=5$ mice in each group; 8 neurons from each mouse; Fig. $8 D, E$ ). The effect of conditional deletion of Oxtr in the proportion of dendritic spine types was also examined (Fig. $8 F$ ).

Statistical analysis. In this study, only adult male mice were used to avoid variations due to hormonal fluctuations during the female estrous cycle, which may influence behavioral and electrophysiological examinations. In some behavioral (Fig. 2), electrophysiological (Figs. 5-7) and neuronal morphological examinations (Fig. 8), age-matched Oxtr ${ }^{\mathrm{f} / \mathrm{f}}$ mice were used as the WT control group. In site-specific manipulation experiments (Figs. 3, 4), Oxtr ${ }^{\mathrm{f} / \mathrm{f}}$ mice receiving AAV-GFP injection were used as the control group and Oxtr ${ }^{\mathrm{f} / \mathrm{f}}$ mice receiving AAV-Cre-GFP injection were used as the treatment group. All experiments were performed on independent cohorts of mice. No statistical methods were used to predetermine sample size, but our sample size choice was based on our previous publications (Lin et al., 2012; Hsiao et al., 2016). Mice were randomly assigned to viral injection experiments, and investigators were blinded to the group allocation while performing cell number counting, behavioral tests, morphological analysis, and electrophysiological recordings. The data were expressed as mean \pm SEM. All statistical analyses were performed using the Prism 6 software package (GraphPad Software; RRID:SCR_002798) or Statistical Package for Social Sciences software (SPSS, v17.0). To compare the difference between the means of two distributions, we first determined whether the distributions of values were Gaussian using the Shapiro-Wilk test. For Gaussian distributions, we calculated $p$ values using paired or unpaired Student's $t$ test, whereas for non-Gaussian distributions we used MannWhitney $U$ test. The average values of the slope of fEPSPs and the amplitude of EPSCs, EPSPs, and IPSCs per time point were analyzed with the Wilcoxon-signed rank test when compared within the same group. Because the distributions of LTP and LTD magnitudes were not Gaussian, the Mann-Whitney $U$ test was used to compare differences between two independent groups. The significance of the difference between multiple groups was calculated by two-way ANOVA followed by Bonferroni's post hoc analyses. The proportion of dendritic spine types was compared with a $\chi^{2}$ test. No experimental data were missing or lost to statistical analysis. Number of animals used is indicated by $n$. Electrophysiological values across multiple slices or neurons from the same animal were averaged to yield a single value for each animal. Probability values of $p<0.05$ were considered to represent significant differences.

\section{Results}

Conditional deletion of Oxtr from CA2 excitatory neurons We first examined the expression of OXTRs in hippocampal CA2 region using Oxtr Venus-Neo/+ mice that express the Venus variant 
A

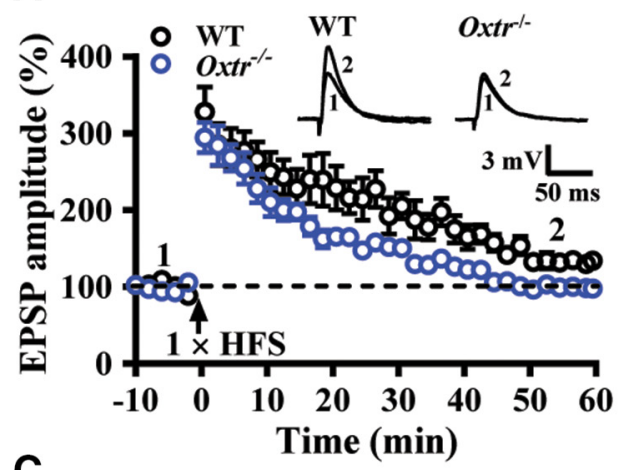

C

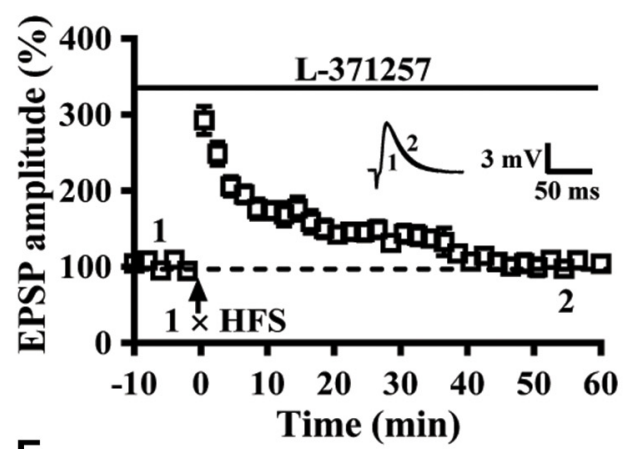

E

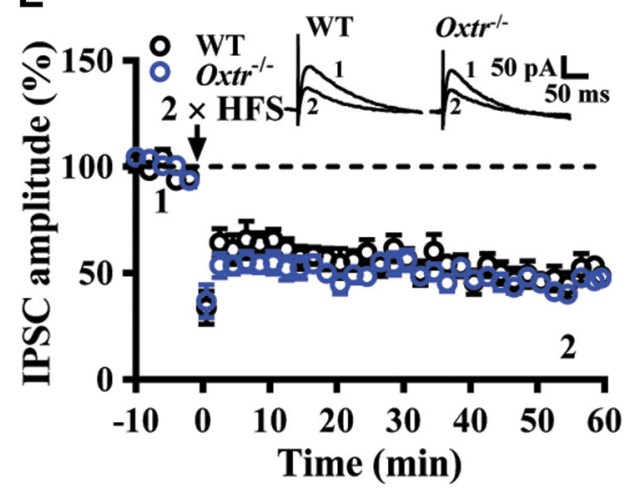

B

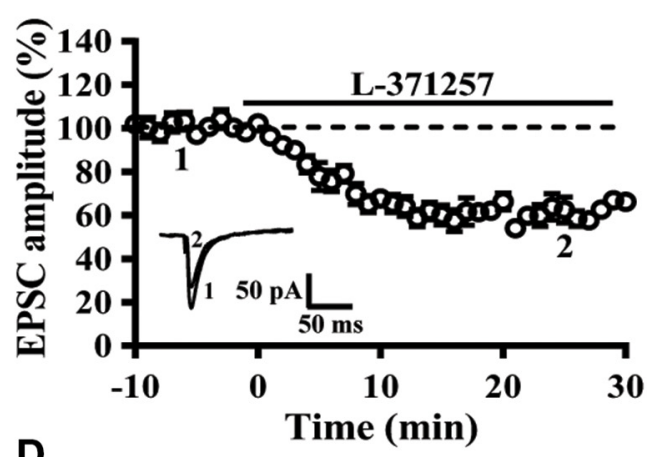

D

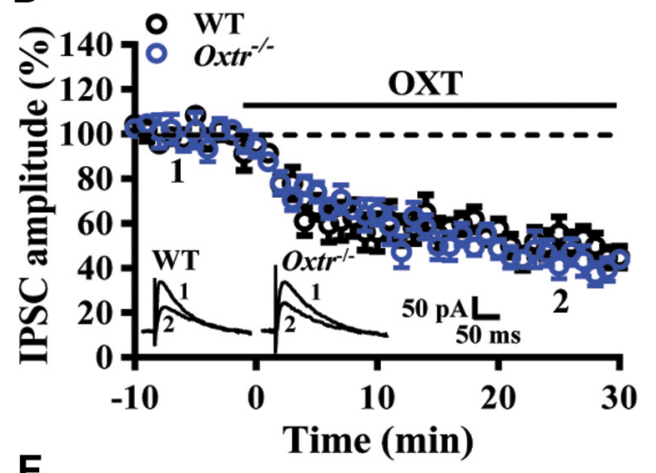

$\mathbf{F}$

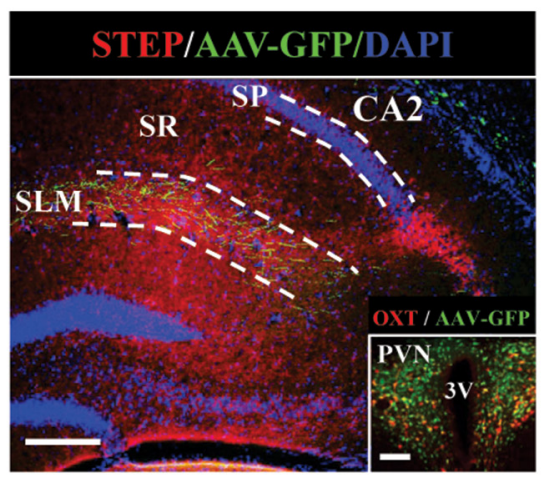

Figure 7. OXTRs are involved in regulating synaptic transmission and plasticity in the CA2. A, Summary of experiments showing one train of $1 \mathrm{~s} H F S$ at $100 \mathrm{~Hz}$ induced LTP of EPSPs at EC $\rightarrow$ CA2 synapses in slices from WT and Oxtr ${ }^{-1-}$ mice. B, Summary of experiments showing effect of $\mathrm{L}-371257(1 \mu \mathrm{M})$ on EPSC amplitude at EC $\rightarrow$ CA2 synapses in slices from naive mice. C, Summary of experiments showing effect of L-371257 $(1 \mu \mathrm{M})$ on the induction of LTP by one train of $1 \mathrm{~s} \mathrm{HFS}$ at $100 \mathrm{~Hz}$ in slices from naive mice. $D$, Summary of experiments showing the effect of $0 X \mathrm{XT}(0.1 \mu \mathrm{m}$ ) on evoked IPSCs in CA2 pyramidal neurons in slices from WT and Oxtr ${ }^{-1-}$ mice. E, Summary of experiments showing two train of $1 \mathrm{~s}$ HFS at $100 \mathrm{~Hz}$ induced LTD of IPSCs in CA2 pyramidal neurons in slices from WT and Oxtr ${ }^{-1-}$ mice. $F$, A representative image showing the distribution of PVN projecting fibers in the SLM of the CA2. Sections were counterstained with DAPI (blue). Inset, OXT neurons in the PVN were labeled with anti-0XT antibody (red) and infected with AAV-Ubi-GFP. Scale bars: $200 \mu \mathrm{m}$; inset, $100 \mu \mathrm{m}$. SP, Stratum pyramidale; SR, stratum radiatum; $3 V$, third ventricle. Representative traces of EPSPS, EPSCs, or IPSCs were taken at the time indicated by number. Dashed lines show level of baseline. The total number of animals examined is indicated by $n$ in parenthesis. Data are represented as mean \pm SEM.

of yellow fluorescent protein in OXTR-expressing cells. Consistent with previous findings (Yoshida et al., 2009; Lin et al., 2017), our immunofluorescent staining data showed strong Venus

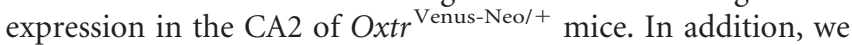
found that $>95 \%$ Venus-positive cells expressed CaMKII $\alpha$ immunoreactivity (Fig. 1A), indicating that OXTRs are predominantly expressed by excitatory pyramidal neurons in the CA2. To examine directly the functional and behavioral relevance of $\mathrm{OX}$ TRs in CA2 pyramidal neurons, we used the Cre-loxP recombination approach to conditionally delete Oxtr from hippocampal excitatory neurons by crossing mice expressing CaMKII $\alpha$-Cre with $O x \mathrm{tr}^{\mathrm{f} / \mathrm{f}}$ mice. PCR screening of mouse genomic tail DNA confirmed heterozygous $\left(\mathrm{Oxtr}^{+/-}\right)$and homozygous Oxtr $\left(\mathrm{Oxtr}^{-/-}\right)$ conditional knock-out mice (Fig. 1B). In parallel, dual-probe
FISH revealed that the majority of Oxtr mRNA-positive cells were CaMKII $\alpha$ mRNA-expressing cells and the number of Oxtrpositive cells in the CA2 of Oxtr ${ }^{-1-}$ mice was markedly reduced compared with that of WT mice (Fig. 1C), confirming the efficiency of Cre-loxP-mediated deletion of Oxtr. Histological evaluation with cresyl violet staining showed that Oxtr deletion did not significantly affect the total number of neurons in the stratum pyramidale of the CA2 compared with that of WT mice $\left(t_{(6)}=\right.$ $1.02, p=0.35$; unpaired Student's $t$ test; Fig. $1 D$ ).

Conditional deletion of CA2/CA3a Oxtr impairs the persistence of long-term SRM

To assess the role of CA2 OXTRs in social behavior, we first compared the performance of WT and $\mathrm{Oxtr}^{-1-}$ mice in a three- 
A

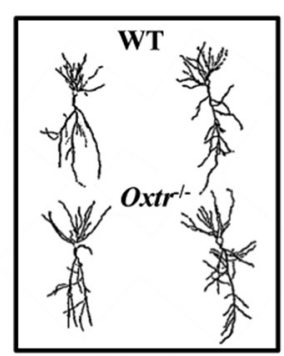

D

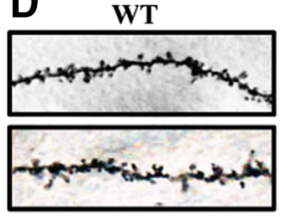

Oxtr ${ }^{1-}$

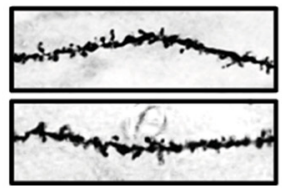

B

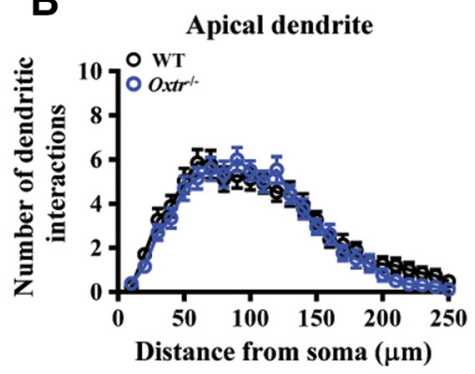

E

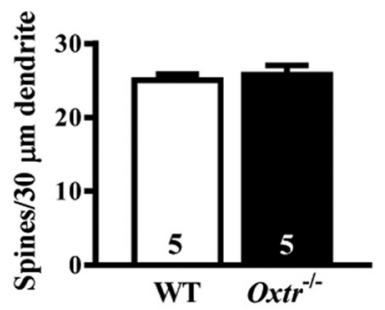

C

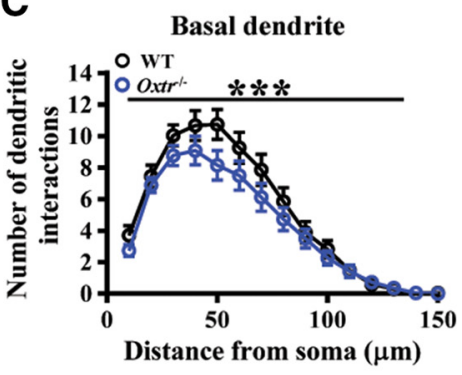

$\mathbf{F}$

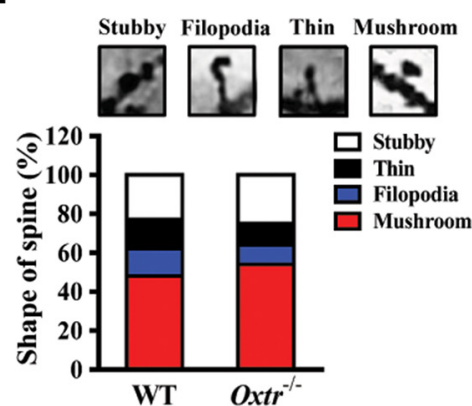

Figure 8. Effect of Oxtr deletion on dendritic morphology and spine density of pyramidal neurons in the hippocampal CA2 region. $A$, Representative camera lucida tracings of hippocampal CA2 pyramidal neurons from WT and $0 x t r{ }^{-1-}$ mice. $\boldsymbol{B}, \boldsymbol{C}$, Sholl analysis of apical (B) basal ( $\boldsymbol{C}$ ) dendrites of CA2 pyramidal neurons from WT and $0 x$ tr $^{-1-}$ mice. $\boldsymbol{D}$, Representative images of the secondary branch of apical dendrites of CA2 pyramidal neurons from WT and $0 x$ tr $^{-1-}$ mice. $E$, Summary bar graphs depicting the density of protrusions in apical dendrites of CA2 pyramidal cells from WT and $\mathrm{Oxtr}^{-1-}$ mice. $\boldsymbol{F}$, Representative images of labeled spines for analysis. Mushroom, filopodia, tine, and stubby spines are identified based on structural measures. There was no significant change in dendritic spine type proportion in $0 x \mathrm{tr}^{-1-}$ mice compared with WT mice. Data represent the mean \pm SEM. ${ }^{* * *} p<0.001$.

chamber test for sociability, which examines the mouse's preference for a chamber containing an unfamiliar stimulus mouse in a wire cage versus a chamber containing an identical empty wire cage. We found no significant difference between WT and Oxtr ${ }^{-1-}$ mice in preference for the chamber containing the stimulus mouse. Difference scores were similar between WT and Oxtr ${ }^{-1-}$ mice in sociability test $\left(t_{(38)}=0.14, p=0.89\right.$; unpaired Student's $t$ test; Fig. 2A). The preference for social novelty was then determined by measuring the preference for a novel mouse compared with the familiar stimulus mouse. As shown in Figure $2 B$, $O x \mathrm{tr}^{-1-}$ mice showed a level of social novelty recognition comparable to that of WT mice. Difference scores were similar between WT and $O x t r^{-1-}$ mice in social novelty test $\left(t_{(38)}=0.10\right.$, $p=0.92$; unpaired Student's $t$ test). When mice were tested SRM $1 \mathrm{~d}$ after the training session (1-d long-term SRM), both WT and $\mathrm{Oxtr}^{-1-}$ mice revealed intact memory retention. They both displayed a significant and similar preference for spending more time exploring the novel mouse than the familiar mouse. Difference scores were similar between WT and $O x t r^{-1-}$ mice in 1-d long-term SRM test $\left(t_{(18)}=0.35, p=0.73\right.$; unpaired Student's $t$ test; Fig. 2C). In contrast, when tested SRM $7 \mathrm{~d}$ after the training session (7-d long-term SRM), Oxtr ${ }^{-1-}$ mice showed no significant difference in the exploration time of the novel and familiar mice $\left(t_{(9)}=0.57, p=0.59\right.$; paired Student's $t$ test), indicating the degree of 7-d long-term SRM was impaired by Oxtr deletion. WT mice, however, spent significantly more time exploring the novel mouse than the familiar mouse $\left(t_{(9)}=6.77, p=0.0001\right.$; paired Student's $t$ test). As a consequence, a statistically significant difference score was observed between WT and Oxtr ${ }^{-1-}$ mice in the degree of 7-d long-term SRM $\left(t_{(18)}=2.97, p=0.008\right.$; unpaired Student's $t$ test; Fig. $2 D$ ). We also conducted a more stringent five-trial social memory assay to examine the contribution of CA2 OXTRs to SRM. In this assay, an ovariectomized stimulus female was present to a resident male mouse for four successive trials. On the fifth trial, a novel ovariectomized stimulus female was introduced. Both WT and Oxtr ${ }^{-1-}$ mice displayed normal SRM, as demonstrated by a characteristic decline in the time spent exploring a previously encountered female during the first four trials and a full recovery following the introduction of a novel female in the fifth trial. A two-way repeated-measure ANOVA revealed no significant effect for the interaction between genotype and test $\left(F_{(4,56)}=1.73, p=0.16\right.$; Fig. $\left.2 E\right)$.

Because Oxtr deletion in Oxtr ${ }^{-1-}$ mice was not restricted to the CA2, the loss of OXTR function in other hippocampal or forebrain regions might also contribute to the observed defect in the persistence of long-term SRM. To circumvent this limitation, in a subset of experiments, we used $O x t r^{\mathrm{f} / \mathrm{f}}$ mice in combination with Cre recombinase-mediated gene deletion in a localized fashion through bilateral stereotaxic injections of AAV-Cre-GFP or control AAV-GFP adenoviral vectors targeting the CA2, under the control of CaMKII $\alpha$ promoter that theoretically restricts expression to excitatory neurons. The successful transduction of AAV-Cre-GFP or AAV-GFP was confirmed by costaining for the CA2-specific marker STEP (Shinohara et al., 2012; Kohara et al., 2014; Fig. 3A). AAV-GFP and AAV-Cre-GFP mice were then subjected to the three-chamber social behavior test. Consistent with the results from $\mathrm{Oxtr}^{-1-}$ mice, AAV-Cre-GFP mice performed similarly to AAV-GFP mice in the sociability $\left(t_{(22)}=0.43\right.$, $p=0.67$; unpaired Student's $t$ test; Fig. $3 B$ ), social novelty recognition $\left(t_{(22)}=0.96, p=0.35\right.$; unpaired Student's $t$ test; Fig. $\left.3 C\right)$ and 1-d long-term SRM $\left(t_{(10)}=0.81, p=0.44\right.$; unpaired Student's $t$ test; Fig. $3 D$ ). In 7-d long-term SRM test, we found that AAV-Cre-GFP mice were unable to discriminate between the novel and familiar mice $\left(t_{(5)}=0.56, p=0.60\right.$; paired Student's $t$ test), whereas AAV-GFP mice were found to have more time investigating the novel mouse than the familiar mouse $t_{(5)}=$ 
2.68, $p=0.04$; paired Student's $t$ test). A statistically significant difference was observed between AAV-Cre-GFP and AAV-GFP mice in the degree of 7-d long-term SRM $\left(t_{(10)}=2.31, p=0.04\right.$; unpaired Student's $t$ test; Fig. $3 E$ ). Because the methodologies we have used to delete Oxtr do not rule out targeting the neighboring $\mathrm{CA} 3 \mathrm{a}$ region, these results suggest that CA2/CA3a Oxtr deletion impairs the persistence of long-term SRM.

\section{Conditional deletion of CA2/CA3a Oxtr does not affect anxiety-like behavior}

It has been shown that OXT can exert anxiolytic effects via OXTRs expressed in serotonergic neurons in mice (Yoshida et al., 2009). We thus examined whether CA2/CA3a Oxtr deletion may alter anxiety-like behavior. Three widely used behavioral tests (OF, EPM, and NSF) were used to evaluate changes in anxietylike behavior. In the OF test, no significant differences in total distance traveled $\left(t_{(18)}=0.68, p=0.51\right.$; unpaired Student's $t$ test; Fig. $4 A$ ) and percentage of time spent in the central zone of the field $\left(t_{(18)}=0.11, p=0.91\right.$; unpaired Student's $t$ test; Fig. $\left.4 B\right)$ were observed in AAV-Cre-GFP mice compared with AAV-GFP mice. In the EPM test, AAV-Cre-GFP mice spent same amounts of time in the open arms $\left(t_{(18)}=0.59, p=0.57\right.$; unpaired Student's $t$ test; Fig. $4 C)$ and the closed arms as AAV-GFP mice $\left(t_{(18)}=\right.$ $0.60, p=0.56$; unpaired Student's $t$ test; Fig. $4 D$ ). In addition, AAV-Cre-GFP and AAV-GFP mice exhibited similar latency to feeding in the NSF test $\left(t_{(18)}=0.24, p=0.82\right.$; unpaired Student's $t$ test; Fig. $4 E$ ). To verify the efficiency and the spread of the viral infection, Oxtr mRNA expression in hippocampal CA1, CA2, and CA3 subregions were examined. qRT-PCR analysis confirmed the specific loss of Oxtr mRNA expression in the CA2 $\left(t_{(18)}=\right.$ 9.54, $p<0.001$; unpaired Student's $t$ test), but not in surrounding CA1 $\left(t_{(18)}=0.61, p=0.56\right.$; unpaired Student's $t$ test $)$ and CA3 regions $\left(t_{(18)}=1.28, p=0.13\right.$; unpaired Student's $t$ test), 3 weeks following the stereotactic injection of AAV-Cre-GFP (Fig. 4F). These results suggest that anxiety-like behavior was not affected by CA2/CA3a Oxtr deletion.

\section{Conditional deletion of CA2/CA3a Oxtr impairs long-term potentiation at $\mathrm{EC} \rightarrow \mathrm{CA} 2$ synapses}

A recent study reported that long-term SRM in rats is mediated by OXT-dependent synaptic plasticity in the medial amygdala (MeA; Gur et al., 2014). In addition, we and others reported previously that OXT can enhance LTP at Schaffer collateral $\rightarrow$ CA1 synapses and improve long-lasting spatial memory function during motherhood (Tomizawa et al., 2003; Lin et al., 2012). To explore further the importance of CA2 OXTRs in long-term SRM formation, we then examined whether the induction of LTP and LTD in the CA2 was affected in Oxtr ${ }^{-1-}$ mice. Although CA2 pyramidal neurons receive bilateral excitatory inputs from CA3 Schaffer collateral on proximal apical dendrites and the EC on distal apical dendrites, only the EC inputs to CA2 neurons have been shown to be capable of undergoing a reliable LTP (Chevaleyre and Siegelbaum, 2010; Chafai et al., 2012). We, therefore, focused on the induction of LTP and LTD at EC $\rightarrow$ CA2 synapses. Extracellular fEPSPs were recorded in the SLM of the CA2 in response to stimulation of EC synaptic inputs (Fig. 5A). In slices from WT mice, a single train of HFS $(100 \mathrm{~Hz}, 1 \mathrm{~s})$ induced a robust LTP (50-60 min after HFS: $52.4 \pm 6.4 \%$ ), whereas a significantly faster decay of LTP was observed in slices from Oxtr ${ }^{-1-}$ mice (50-60 min after HFS: $21.9 \pm 4.3 \%, p=0.001$; Mann-Whitney $U$ test; Fig. $5 B, D)$, suggesting that Oxtr deletion impairs the maintenance of LTP. In contrast, we observed no significant difference between WT and Oxtr ${ }^{-1-}$ mice in the induction of LTP by a stronger tetanizing protocol, consisting of two trains of HFS (50-60 min after HFS: WT mice, $58.2 \pm 4.4 \%$; Oxtr ${ }^{-1-}$ mice, $44.8 \pm 5.6 \%, p=0.31$; Mann-Whitney $U$ test; Fig. $5 C, D)$. However, in slices from both WT and Oxtr ${ }^{-1-}$ mice, no significant LTD was observed after LFS (50-60 min after the end of LFS: WT mice, $3.5 \pm 6.9 \%$; Oxtr ${ }^{-1-}$ mice, $12.8 \pm 5.3 \%, p=0.31$; MannWhitney $U$ test; Fig. $5 E, F)$.

We next examined whether OXT is directly involved in the regulation of synaptic transmission in the CA2. CA2 pyramidal neurons in slices from naive mice were targeted for recording, filled with biocytin to allow post hoc reconstruction (Fig. 6A). In these experiments, EPSCs were evoked in CA2 pyramidal neurons in response to stimulation of the EC inputs. As shown in Figure $6, B$ and $D$, bath application of the selective OXTR agonist [Thr ${ }^{4}, \mathrm{Gly}^{7}$ ]-OXT $(0.1 \mu \mathrm{M})$ for $20 \mathrm{~min}$ resulted in a slowly developing potentiation of EPSCs in slices from WT mice (28.4 \pm $4.1 \%)$, whereas $\left[\mathrm{Thr}^{4}, \mathrm{Gly}^{7}\right]$-OXT failed to change EPSCs in slices from $O x$ tr $^{-1-}$ mice $\left(2.3 \pm 3.9 \%, t_{(14)}=4.56, p<0.001\right.$; unpaired Student's $t$ test). Looking for molecular mechanisms responsible for $\left[\mathrm{Thr}^{4}, \mathrm{Gly}^{7}\right]$-OXT-induced synaptic potentiation, we focused on the specific roles of NMDAR and CaMKII, which have been shown to be activated after OXTR stimulation (Jurek et al., 2015; Pagani et al., 2015; van den Burg et al., 2015). To this end, a selective NMDAR antagonist APV and a broad spectrum CaMKII inhibitor KN93 were used. We found that APV $(50 \mu \mathrm{M})$ prevented $\left[\mathrm{Thr}^{4}, \mathrm{Gly}^{7}\right]$-OXT-induced synaptic potentiation $\left(1.6 \pm 4.2 \%, t_{(12)}=4.48, p<0.001\right.$; unpaired Student's $t$ test $)$. In addition, pretreatment of the hippocampal slices with KN93 (1 $\mu \mathrm{M} ; 8.4 \pm 3.6 \%, t_{(12)}=3.52, p<0.01$; unpaired Student's $t$ test), but not its inactive structural analog KN92 (1 $\mu \mathrm{M} ; 30.5 \pm$ $3.4 \%, t_{(12)}=0.38, p=0.71$; unpaired Student's $t$ test), completely blocked $\left[\mathrm{Thr}^{4}, \mathrm{Gly}^{7}\right]$-OXT-induced synaptic potentiation (Fig. 6C,D).

Because CA2 and CA3 dendrites comingle in the SLM of the CA2, the extracellular field potential recordings may not selectively monitor CA2 synaptic responses. We thus repeated the LTP experiments in whole-cell current-clamp recordings of CA2 pyramidal neurons conducted in the presence of gabazine $(10 \mu \mathrm{M})$ and CGP55845 $(2 \mu \mathrm{M})$ to block GABAergic inhibitory transmission. In slices from WT mice, a single train of HFS $(100 \mathrm{~Hz}, 1 \mathrm{~s})$ induced a LTP of EPSPs (50-60 min after HFS: $34.3 \pm 7.1 \%)$, whereas a significantly faster decay of LTP was observed in slices from $O x t r^{-1-}$ mice (50-60 min after HFS: $1.7 \pm 3.9 \%, p<0.01$; Mann-Whitney $U$ test; Fig. 7A), confirming that Oxtr deletion impairs the maintenance of LTP. As removing OXTRs could also lead to alterations in other receptors or signaling pathways, we also examined whether acute blockade of OXTRs may block LTP induction at $\mathrm{EC} \rightarrow \mathrm{CA} 2$ synapses. We first checked the effect of the selective OXTR antagonist L-371257 on basal synaptic transmission. As shown in Figure $7 B$, application of L-371257 (1 $\mu \mathrm{M})$ caused a significant $35.8 \pm 2.3 \%$ decrease in EPSC amplitude. Furthermore, as we observed using Oxtr ${ }^{-1-}$ mice, LTP of EPSP was completely blocked in the presence of L-371257 (1 $\mu \mathrm{M} ; 50-60$ min after HFS: $3.1 \pm 5.6 \%, p<0.001$; Mann-Whitney $U$ test; Fig. 7C).

Because OXTRs are also often expressed by inhibitory neurons (Yoshida et al., 2009; Owen et al., 2013; Lin et al., 2017), we determined whether OXTRs control basal transmission and synaptic plasticity at inhibitory synapses. We first measured the effect of OXT on IPSCs in CA2 pyramidal neurons. Application of $\left[\mathrm{Thr}^{4}\right.$,Gly ${ }^{7}$ ]-OXT $(0.1 \mu \mathrm{M})$ significantly decreased the amplitude of evoked IPSCs by $48.6 \pm 5.3 \%$ and $52.3 \pm 4.9 \%$, in neurons from WT and $O x t r^{-1-}$ mice, respectively $\left(t_{(6)}=1.14, p=0.21\right.$; 
unpaired Student's $t$ test; Fig. 7D). Consistent with previous work (Piskorowski and Chevaleyre, 2013), we found that a HFS triggered a robust LTD of IPSC amplitude of CA2 pyramidal neurons. There was no significant difference in the magnitude of LTD between neurons obtained from WT (50-60 min after HFS: $54.3 \pm 4.9 \%)$ and $O x t r^{-1-}$ mice (50-60 min after HFS: $53.1 \pm$ $5.2 \%, p=0.81$; Mann-Whitney $U$ test; Fig. $7 E$ ). These results indicate that the regulatory effects of OXT on synaptic transmission and plasticity at inhibitory synapses were not affected by conditional deletion of Oxtr from CA2 excitatory neurons. Combined with viral tracing and immunostaining with antiOXT antibody, we confirmed that PVN neurons send their OXT-containing projecting fibers directly to the SLM of the CA2 (Fig. 7F).

\section{Conditional deletion of Oxtr reduces basal dendrite complexity of CA2 pyramidal neurons}

To examine whether Oxtr deletion may influence dendritic geometry and spine density, we used Golgi-Cox staining to visualize individual CA2 pyramidal neurons in WT and Oxtr ${ }^{-1-}$ mice (Fig. 8A), and analyzed the complexity of their dendritic trees. Sholl analysis of reconstructed CA2 pyramidal neurons revealed that Oxtr deletion had no effect on the complexity of apical dendrites $\left(F_{(1,1250)}=2.39, p=0.12\right.$; two-way ANOVA; Fig. $\left.8 B\right)$ but significantly decreased basal dendrite branching $\left(F_{(1,764)}=12.50\right.$, $p=0.0004$; two-way ANOVA; Fig. $8 C)$. No significant change in the density of dendritic spine was detected on secondary and tertiary branches of apical dendrites of CA2 pyramidal neurons in $O x \mathrm{tr}^{-1-}$ mice compared with that of WT mice $\left(t_{(8)}=0.49, p=\right.$ 0.64 ; unpaired Student's $t$ test; Fig. $8 D, E)$. Additional analysis revealed no significant alteration in the proportion of dendritic spine types in $O x \mathrm{tr}^{-1-}$ mice compared with that of WT mice $\left(\chi^{2}=1.72, p=0.63 ; \chi^{2}\right.$ test; Fig. $\left.8 F\right)$.

\section{Discussion}

Our study, for the first time, reveals the critical contribution of CA2/CA3a OXTRs to the persistence of long-term SRM. We confirm that OXTRs are enriched in the CA2 of the mouse hippocampus and show that pharmacological activation of OXTRs produces synaptic potentiation through a mechanism dependent on the NMDAR-mediated activation of CaMKII. Conditional deletion of CA2/CA3a Oxtr leads to impaired LTP at EC $\rightarrow$ CA2 synapses and produces a pronounced loss of the ability to create a persistent form of long-term SRM, without affecting anxiety-like behavior. As CA2 and CA3 pyramidal neurons are highly intermingled at the border region (Hitti and Siegelbaum, 2014) and OXTRs are also highly expressed in CA3 pyramidal neurons (Lin et al., 2017), the methodologies we have used to delete Oxtr do not rule out targeting the neighboring CA3a region. Although we think that CA2 OXTRs may be most critical for the persistence of long-term SRM, at this point this is conjecture that is not supported by direct experimental evidence.

Although previous studies have underscored the importance of hippocampal CA2 neurons in SRM formation (Hitti and Siegelbaum, 2014; Stevenson and Caldwell, 2014), they have focused solely on the functional assessment, with only a few addressing its mode of action. A recent study has shown that pharmacological antagonism of the vasopressin (AVP) 1 b receptors in the CA2 blocked the enhancement of SRM induced by optogenetic stimulation of AVP projection neurons from the PVN, suggesting an enhancing effect of AVP on social memory formation (Smith et al., 2016). Here, we extend these findings by demonstrating that mice lacking CA2/CA3a OXTRs have a defect in the persistence of long-term SRM. Consistent with previous work (Kogan et al., 2000), we show that adult C57BL/6 mice can form robust longterm SRM for juvenile conspecifics and this memory can be maintained for at least $7 \mathrm{~d}$. Our findings that memory retention was unaffected at $1 \mathrm{~d}$ after training but significantly impaired at $7 \mathrm{~d}$ after training in mice lacking CA2/CA3a Oxtr suggest that OXTR signaling is specifically critical for the persistence of longterm SRM. These results imply the existence of a CA2/CA3a OXTR-dependent information processing phase to specifically transform a rapidly decaying memory trace into a persistent form of long-term SRM. Although the exact mechanisms that trigger this OXTR-dependent phase remain to be elucidated, one possibility is that, during training, a OXTR-induced gene transcription and de novo protein synthesis process that may last for several hours or even days is switched on and then to ensure memory persistence. Of note, previous studies showed that brain-derived neurotrophic factor (BDNF) can induce a late postacquisition phase in the hippocampus essential for persistence of long-term memory storage (Bekinschtein et al., 2007, 2008; Nakayama et al., 2015). Therefore, it is possible that the molecular mechanism by which OXTRs promote persistence of long-term SRM is associated with increased BDNF protein levels. This assertion is also supported by a study showing that intranasal administration of OXT can increase hippocampal BDNF levels in rats subjected to chronic restraint stress (Dayi et al., 2015). Furthermore, the impact of OXTR signaling on long-term SRM is not limited to hippocampal CA2/CA3a region. A recent study has shown that the accessory olfactory bulb (AOB)-MeA pathway also contributes to OXT's regulation of long-term SRM in rats (Gur et al., 2014), suggesting that multiple discrete brain regions are involved in OXT-mediated regulation of long-term SRM.

OXT has been shown to modulate synaptic plasticity in multiple brain regions. We and others have previously demonstrated that OXT can enhance LTP at hippocampal Schaffer collateral $\rightarrow$ CA1 synapses (Tomizawa et al., 2003; Lin et al., 2012) and AOB mitral cell $\rightarrow$ granule cell synapses (Fang et al., 2008). Treatment of brain slices with OXT was observed to convert LTD into LTP in the infralimbic medial prefrontal cortex (Ninan, 2011). In addition, OXT was shown to facilitate LTD induction in the AOBMeA pathway (Gur et al., 2014). Here, we extend these findings by demonstrating that OXTR signaling is necessary for LTP induction at EC $\rightarrow$ CA2 synapses. Because the role of OXTR signaling in LTP was not affected by blocking GABAergic inhibition, it is unlikely that OXT exerts its effect on LTP through a disinhibitory mechanism to drive firing in CA2 pyramidal neurons. We further confirm that OXT agonist can induce synaptic potentiation at $\mathrm{EC} \rightarrow \mathrm{CA} 2$ synapses. Using the pharmacological inhibitors and $\mathrm{Oxtr}^{-1-}$ mice, we indicate that OXT agonist-induced synaptic potentiation relies on the activation of OXTRs and is dependent on NMDAR and CaMKII activity. Our data support a model in which the activation of OXTRs leads to increased intracellular $\mathrm{Ca}^{2+}$ concentration $\left(\left[\mathrm{Ca}^{2+}\right]_{\mathrm{i}}\right)$ and thereby activates CaMKII, which promotes AMPA receptor recruitment at synapses to support synaptic potentiation. Furthermore, NMDARs may act synergistically with the $\left[\mathrm{Ca}^{2+}\right]_{\mathrm{i}}$ rise in mediating this synaptic potentiation. Interestingly, activation of NMDARs and CaMKII were also described in AVP agonist-induced synaptic potentiation at Schaffer collateral $\rightarrow$ CA2 synapses (Pagani et al., 2015). Based on our Venus immunoreactivity assay, OXTRs appear to be mainly expressed in the stratum pyramidale and stratum oriens. This raises an interesting question about how receptors located on the soma and basal dendrites of pyramidal neurons can control plasticity of distal inputs far away from the 
receptor location? Although the precise mechanism remains unclear, a possible explanation is that OXTRs may transmit signals from the soma to distal dendrites through intracellular second messenger systems following receptor activation. Additional studies are needed to clarify this issue.

Our analysis of neuronal morphology reveals a significant decrease in basal dendrite complexity of CA2 pyramidal neurons in $\mathrm{Oxtr}^{-1-}$ mice, suggesting a compartmentalized regulation of OXTR signaling on neuronal morphology. This finding seems to contrast with a recent study showing that deletion of Oxtr in the hippocampus promotes dendrite overgrowth in CA1 and CA3 pyramidal neurons (Ripamonti et al., 2017). The reason for this discrepancy is unclear but could be related to the fact that CA2 pyramidal neurons have distinct anatomical or molecular features compared with CA1 and CA3 pyramidal neurons (Ishizuka et al., 1995; Dudek et al., 2016). In analogy, we did not observe a significant change in the density of apical dendritic spines of CA2 pyramidal neurons in Oxtr ${ }^{-1-}$ mice, whereas Ripamonti et al. (2017) reported that Oxtr deletion increases the density of filopodia and filopodia-like protrusions along the apical dendrites of CA1 pyramidal neurons. Although it is reasonable to speculate that changes in dendritic arborization may lead to altered neuronal signaling and function, the link between the decrease in basal dendrites and the effects of OXTRs on synaptic plasticity and long-term SRM remains to be further elucidated. It remains unclear why the complexity of basal dendrites is more prominently affected by Oxtr deletion than apical dendrites in $\mathrm{Oxtr}^{-1-}$ mice. Because basal dendrites of CA2 pyramidal neurons receive dense inputs from CA3 neurons (Dudek et al., 2016) and OXTRs are highly expressed in CA3 pyramidal neurons (Lin et al., 2017), it is plausible that higher responsiveness of basal dendrites of CA2 pyramidal neurons in response to Oxtr deletion is partially due to the concomitant loss of stimulating effect that comes from OXTR-expressing CA3 pyramidal neurons.

Consistent with the idea that long-term memory storage relies on LTP induction (Mayford et al., 2012; Takeuchi et al., 2013), our results demonstrated a strong correlation between hippocampal CA2 LTP and long-term SRM formation. Our observations that Oxtr deletion impairs the maintenance of LTP at $\mathrm{EC} \rightarrow \mathrm{CA} 2$ synapses and the persistence of long-term SRM support the notion that the excitatory inputs from the EC to CA2 pyramidal neurons are crucial for hippocampal function and memory formation (Hitti and Siegelbaum, 2014; Dudek et al., 2016). Indeed, it has been proposed that CA2 pyramidal neurons form the nexus of a powerful disynaptic circuit linking EC input with CA1 output to mediate key aspects of hippocampal function (Chevaleyre and Siegelbaum, 2010). Therefore, it is likely that activation of OXTRs promotes the EC inputs to CA2 pyramidal neurons to undergo LTP that enhances the excitatory drive of hippocampal circuit for creating persistent long-term SRM traces.

Whereas numerous studies have demonstrated that endogenous OXT has anxiolytic actions (Mantella et al., 2003; Crawley et al., 2007; Yoshida et al., 2009; Neumann and Slattery, 2016), the results reported here show no significant alterations in anxietylike behavior in mice with conditionally deleted CA2/CA3a Oxtr, as evidenced by measuring performance in the OF, EPM, and NSF, suggesting that the CA2/CA3a may not be critically involved in the regulation of anxiety-like behavior by OXT. In this context, it has been previously proposed that OXT exerts its anxiolytic effects via OXTRs expressed in serotonergic neurons of the raphe nuclei (Yoshida et al., 2009).

In conclusion, our results reveal a pivotal role for the CA2/ CA3a in long-term SRM formation and suggest a mechanism by which OXTR activity induces synaptic potentiation to promote the persistence of long-term memory storage. These findings provide important insights into the importance of CA2/CA3a OXTR signaling in regulating the persistence of long-term SRM and suggest a new target for therapeutic approaches to the treatment of social cognition deficits, often observed in patients with neuropsychiatric disorders.

\section{References}

Bekinschtein P, Cammarota M, Igaz LM, Bevilaqua LR, Izquierdo I, Medina JH (2007) Persistence of long-term memory storage requires a late protein synthesis- and BDNF-dependent phase in the hippocampus. Neuron 53:261-277. CrossRef Medline

Bekinschtein P, Cammarota M, Katche C, Slipczuk L, Rossato JI, Goldin A, Izquierdo I, Medina JH (2008) BDNF is essential to promote persistence of long-term memory storage. Proc Natl Acad Sci U S A 105:2711-2716. CrossRef Medline

Bird CM, Burgess N (2008) The hippocampus and memory: insights from spatial processing. Nat Rev Neurosci 9:182-194. CrossRef Medline

Buijs RM, Swaab DF (1979) Immuno-electron microscopical demonstration of vasopressin and oxytocin synapses in the limbic system of the rat. Cell Tissue Res 204:355-365. Medline

Chafai M, Corbani M, Guillon G, Desarménien MG (2012) Vasopressin inhibits LTP in the CA2 mouse hippocampal area. PLoS One 7:e49708. CrossRef Medline

Chevaleyre V, Piskorowski RA (2016) Hippocampal area CA2: an overlooked but promising therapeutic target. Trends Mol Med 22:645-655. CrossRef Medline

Chevaleyre V, Siegelbaum SA (2010) Strong CA2 pyramidal neuron synapses define a powerful disynaptic cortico-hippocampal loop. Neuron 66:560-572. CrossRef Medline

Crawley JN, Chen T, Puri A, Washburn R, Sullivan TL, Hill JM, Young NB, Nadler JJ, Moy SS, Young LJ, Caldwell HK, Young WS 3rd (2007) Social approach behaviors in oxytocin knock-out mice: comparison of two independent lines tested in different laboratory environments. Neuropeptides 41:145-163. CrossRef Medline

Cui Z, Gerfen CR, Young WS 3rd (2013) Hypothalamic and other connections with dorsal CA2 area of the mouse hippocampus. J Comp Neurol 521:1844-1866. CrossRef Medline

Dayi A, Cetin F, Sisman AR, Aksu I, Tas A, Gönenc S, Uysal N (2015) The effects of oxytocin on cognitive defect caused by chronic restraint stress applied to adolescent rats and on hippocampal VEGF and BDNF levels. Med Sci Monit 21:69-75. CrossRef Medline

Dudek SM, Alexander GM, Farris S (2016) Rediscovering area CA2: unique properties and functions. Nat Rev Neurosci 17:89-102. CrossRef Medline

Fang LY, Quan RD, Kaba H (2008) Oxytocin facilitates the induction of long-term potentiation in the accessory olfactory bulb. Neurosci Lett 438: 133-137. CrossRef Medline

Franklin K, and Paxinos G (2008) The mouse brain in stereotaxic coordinates. San Diego: Elsevier Academic.

Gimpl G, Fahrenholz F (2001) The oxytocin receptor system: structure, function, and regulation. Physiol Rev 81:629-683. CrossRef Medline

Grinevich V, Knobloch-Bollmann HS, Eliava M, Busnelli M, Chini B (2016) Assembling the puzzle: pathways of oxytocin signaling in the brain. Biol Psychiatry 79:155-164. CrossRef Medline

Gross C, Zhuang X, Stark K, Ramboz S, Oosting R, Kirby L, Santarelli L, Beck $S$, Hen R (2002) Serotonin1A receptor acts during development to establish normal anxiety-like behaviour in the adult. Nature 416:396-400. CrossRef Medline

Gur R, Tendler A, Wagner S (2014) Long-term social recognition memory is mediated by oxytocin-dependent synaptic plasticity in the medial amygdala. Biol Psychiatry 76:377-386. CrossRef Medline

Haglund L, Swanson LW, Köhler C (1984) The projection of the supramammillary nucleus to the hippocampal formation: an immunohistochemical and anterograde transport study with the lectin PHA-L in the rat. J Comp Neurol 229:171-185. CrossRef Medline

Hitti FL, Siegelbaum SA (2014) The hippocampal CA2 region is essential for social memory. Nature 508:88-92. CrossRef Medline

Hsiao YM, Tsai TC, Lin YT, Chen CC, Huang CC, Hsu KS (2016) Early life stress dampens stress responsiveness in adolescence: evaluation of neuroendocrine reactivity and coping behavior. Psychoneuroendocrinology 67:86-99. CrossRef Medline 
Huang CC, Chu CY, Yeh CM, Hsu KS (2014) Acute hypernatremia dampens stress-induced enhancement of long-term potentiation in the dentate gyrus of rat hippocampus. Psychoneuroendocrinology 46: 129-140. CrossRef Medline

Insel TR, Fernald RD (2004) How the brain processes social information: searching for the social brain. Annu Rev Neurosci 27:697-722. CrossRef Medline

Ishizuka N, Cowan WM, Amaral DG (1995) A quantitative analysis of the dendritic organization of pyramidal cells in the rat hippocampus. J Comp Neurol 362:17-45. CrossRef Medline

Jurek B, Slattery DA, Hiraoka Y, Liu Y, Nishimori K, Aguilera G, Neumann ID, van den Burg EH (2015) Oxytocin regulates stress-induced Crf gene transcription through CREB-regulated transcription coactivator 3. J Neurosci 35:12248-12260. CrossRef Medline

Kogan JH, Frankland PW, Silva AJ (2000) Long-term memory underlying hippocampus-dependent social recognition in mice. Hippocampus 10: 47-56. CrossRef Medline

Kohara K, Pignatelli M, Rivest AJ, Jung HY, Kitamura T, Suh J, Frank D, Kajikawa K, Mise N, Obata Y, Wickersham IR, Tonegawa S (2014) Cell type-specific genetic and optogenetic tools reveal hippocampal CA2 circuits. Nat Neurosci 17:269-279. CrossRef Medline

Lee HJ, Macbeth AH, Pagani JH, Young WS 3rd (2009) Oxytocin: the great facilitator of life. Prog Neurobiol 88:127-151. CrossRef Medline

Lin YT, Huang CC, Hsu KS (2012) Oxytocin promotes long-term potentiation by enhancing epidermal growth factor receptor-mediated local translation of protein kinase M $\zeta$. J Neurosci 32:15476-15488. CrossRef Medline

Lin YT, Chen CC, Huang CC, Nishimori K, Hsu KS (2017) Oxytocin stimulates hippocampal neurogenesis via oxytocin receptor expressed in CA3 pyramidal neurons. Nat Commun 8:537. CrossRef Medline

Lorente de Nó R (1934) Studies on the structure of the cerebral cortex: II. Continuation of the study of the ammonic system. J Psychol Neurol 46:113-177.

Mantella RC, Vollmer RR, Li X, Amico JA (2003) Female oxytocin-deficient mice display enhanced anxiety-related behavior. Endocrinology 144: 2291-2296. CrossRef Medline

Maroun M, Wagner S (2016) Oxytocin and memory of emotional stimuli: some dance to remember, some dance to forget. Biol Psychiatry 79:203212. CrossRef Medline

Mayford M, Siegelbaum SA, Kandel ER (2012) Synapses and memory storage. Cold Spring Harb Perspect Biol 4:a005751. CrossRef Medline

Meyer-Lindenberg A, Domes G, Kirsch P, Heinrichs M (2011) Oxytocin and vasopressin in the human brain: social neuropeptides for translational medicine. Nat Rev Neurosci 12:524-538. CrossRef Medline

Mitre M, Marlin BJ, Schiavo JK, Morina E, Norden SE, Hackett TA, Aoki CJ, Chao MV, Froemke RC (2016) A distributed network for social cognition enriched for oxytocin receptors. J Neurosci 36:2517-2535. CrossRef Medline

Moy SS, Nadler JJ, Perez A, Barbaro RP, Johns JM, Magnuson TR, Piven J, Crawley JN (2004) Sociability and preference for social novelty in five inbred strains: an approach to assess autistic-like behavior in mice. Genes Brain Behav 3:287-302. CrossRef Medline

Nakayama D, Iwata H, Teshirogi C, Ikegaya Y, Matsuki N, Nomura H (2015) Long-delayed expression of the immediate early gene Arc/Arg3.1 refines neuronal circuits to perpetuate fear memory. J Neurosci 35:819-830. CrossRef Medline

Neumann ID (2008) Brain oxytocin: a key regulator of emotional and social behaviors in both females and males. J Neuroendocrinol 20:858-865. CrossRef Medline

Neumann ID, Landgraf R (2008) Advances in vasopressin and oxytocinfrom genes to behavior to disease. Prog Brain Res 170:xi-xiii. CrossRef Medline

Neumann ID, Slattery DA (2016) Oxytocin in general anxiety and social fear: a translational approach. Biol Psychiatry 79:213-221. CrossRef Medline

Ninan I (2011) Oxytocin suppresses basal glutamatergic transmission but facilitates activity-dependent synaptic potentiation in the medial prefrontal cortex. J Neurochem 119:324-331. CrossRef Medline
Owen SF, Tuncdemir SN, Bader PL, Tirko NN, Fishell G, Tsien RW (2013) Oxytocin enhances hippocampal spike transmission by modulating fastspiking interneurons. Nature 500:458-462. CrossRef Medline

Pagani JH, Zhao M, Cui Z, Avram SK, Caruana DA, Dudek SM, Young WS (2015) Role of the vasopressin $1 \mathrm{~b}$ receptor in rodent aggressive behavior and synaptic plasticity in hippocampal area CA2. Mol Psychiatry 20:490 499. CrossRef Medline

Pellow S, Chopin P, File SE, Briley M (1985) Validation of open:closed arm entries in an elevated plus-maze as a measure of anxiety in the rat. J Neurosci Methods 14:149-167. CrossRef Medline

Pikkarainen M, Rönkkö S, Savander V, Insausti R, Pitkänen A (1999) Projections from the lateral, basal, and accessory basal nuclei of the amygdala to the hippocampal formation in rat. J Comp Neurol 403:229-260. CrossRef Medline

Piskorowski RA, Chevaleyre V (2013) Delta-opioid receptors mediate unique plasticity onto parvalbumin-expressing interneurons in area CA2 of the hippocampus. J Neurosci 33:14567-14578. CrossRef Medline

Ripamonti S, Ambrozkiewicz MC, Guzzi F, Gravati M, Biella G, Bormuth I, Hammer M, Tuffy LP, Sigler A, Kawabe H, Nishimori K, Toselli M, Brose N, Parenti M, Rhee J (2017) Transient oxytocin signaling primes the development and function of excitatory hippocampal neurons. eLife 6:e22466. CrossRef Medline

Shinohara Y, Hosoya A, Yahagi K, Ferecskó AS, Yaguchi K, Sík A, Itakura M, Takahashi M, Hirase H (2012) Hippocampal CA3 and CA2 have distinct bilateral innervation patterns to CA1 in rodents. Eur J Neurosci 35:702-710. CrossRef Medline

Smith AS, Williams Avram SK, Cymerblit-Sabba A, Song J, Young WS (2016) Targeted activation of the hippocampal CA2 area strongly enhances social memory. Mol Psychiatry 21:1137-1144. CrossRef Medline

Sofroniew MV (1983) Morphology of vasopressin and oxytocin neurons and their central and vascular projections. Prog Brain Res 60:101-114. CrossRef Medline

Stevenson EL, Caldwell HK (2014) Lesions to the CA2 region of the hippocampus impair social memory in mice. Eur J Neurosci 40:3294-3301. CrossRef Medline

Takeuchi T, Duszkiewicz AJ, Morris RG (2013) The synaptic plasticity and memory hypothesis: encoding, storage and persistence. Philos Trans R Soc Lond B Biol Sci 369:20130288. CrossRef Medline

Tomizawa K, Iga N, Lu YF, Moriwaki A, Matsushita M, Li ST, Miyamoto O, Itano T, Matsui H (2003) Oxytocin improves long-lasting spatial memory during motherhood through MAP kinase cascade. Nat Neurosci 6:384-390. CrossRef Medline

Tyler WJ, Pozzo-Miller L (2003) Miniature synaptic transmission and BDNF modulate dendritic spine growth and form in rat CA1 neurones. J Physiol 553:497-509. CrossRef Medline

van den Burg EH, Stindl J, Grund T, Neumann ID, Strauss O (2015) Oxytocin stimulates extracellular $\mathrm{Ca}^{2+}$ influx through TRPV2 channels in hypothalamic neurons to exert its anxiolytic effects. Neuropsychopharmacology 40:2938-2947. CrossRef Medline

Wang YT, Huang CC, Lin YS, Huang WF, Yang CY, Lee CC, Yeh CM, Hsu KS (2017) Conditional deletion of Eps8 reduces hippocampal synaptic plasticity and impairs cognitive function. Neuropharmacology 112:113-123. CrossRef Medline

Yang CH, Huang CC, Hsu KS (2012) A critical role for protein tyrosine phosphatase nonreceptor type 5 in determining individual susceptibility to develop stress-related cognitive and morphological changes. J Neurosci 32:7550-7762. CrossRef Medline

Yoshida M, Takayanagi Y, Inoue K, Kimura T, Young LJ, Onaka T, Nishimori K (2009) Evidence that oxytocin exerts anxiolytic effects via oxytocin receptor expressed in serotonergic neurons in mice. J Neurosci 29:2259_ 2271. CrossRef Medline

Young WS 3rd, Gainer H (2003) Transgenesis and the study of expression, cellular targeting and function of oxytocin, vasopressin and their receptors. Neuroendocrinology 78:185-203. CrossRef Medline

Zhang L, Hernández VS (2013) Synaptic innervation to rat hippocampus by vasopressin-immuno-positive fibres from the hypothalamic supraoptic and paraventricular nuclei. Neuroscience 228:139-162. CrossRef Medline 